UCRL-ID-124702

\title{
Modeling Impurities and Tilted Plates in the ITER Divertor
}

M.E. Rensink and T. D. Rognlien

July 29, 1996

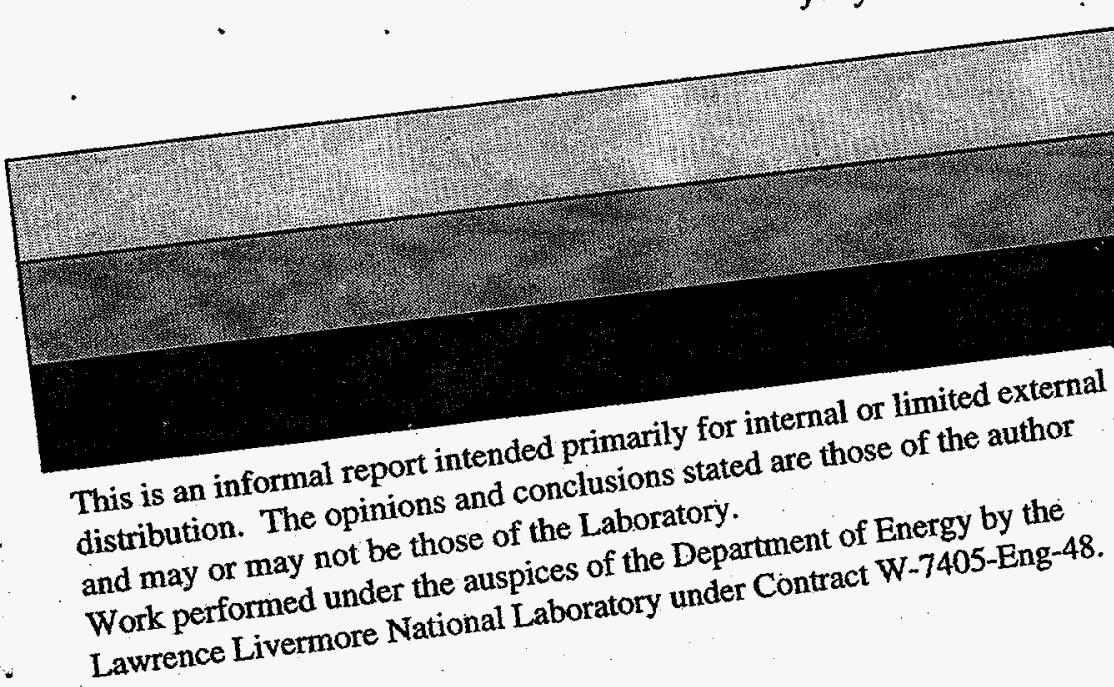

DISTRIBUTION OF THIS DOCUMENT IS UNLIMITED, 


\section{DISCLAIMER}

This document was prepared as an account of work sponsored by an agency of the United States Government. Neither the United States Government nor the University of California nor any of their employees, makes any waranty, express or implied, or assumes any legal liability or responsibility for the accuracy, completeness, or usefulness of any information, apparatus, product, or process disclosed, or represents that its use would not infringe privately owned rights. Reference herein to any specific commercial product, process, or service by trade name, trademark, manufacturer, or otherwise, does not necessarily constitute or imply its endorsement, recommendation, or favoring by the United States Government or the University of California. The views and opinions of authors expressed herein do not necessarily state or reflect those of the United States Government or the University of California, and shall not be used for advertising or product endorsement purposes.

This report has been reproduced directly from the best available copy.

Available to DOE and DOE contractors from the

Office of Scientific and Technical Information

P.O. Box 62, Oak Ridge, TN 37831

Prices available from (615) 576-8401, FTS 626-8401

Available to the public from the

National Technical Information Service

U.S. Department of Commerce

5285 Port Royal Rd.

Springfield, VA 22161 


\section{DISCLAIMER}

Portions of this document may be illegible in electronic image products. Images are produced from the best available original document. 
July 29,1996

\title{
Modeling Impurities and Tilted Plates in the ITER Divertor
}

\author{
M.E. Rensink and T.D. Rognlien \\ Lawrence Livermore National Laboratory \\ Livermore, CA 94551
}

The UEDGE 2-D edge transport code is used to model the effect of impurities and tilted divertor plates for the ITER SOL/divertor region. The impurities are modeled as individual charge states using either the FMOMBAL 21-moment description or parallel force balance. Both helium and neon impurities are used together with a majority hydrogenic species. A fluid description of the neutrals is used that includes parallel inertia and neutral-neutral collisions. Effects of geometry are analyzed by using the nonorthogonal mesh capability of UEDGE to obtain solutions with the divertor plate tilted at various angles. 


\section{Contents}

I Introduction

II Geometry and Equations

IIIResults of ITER Simulations

A Parameters and Coefficients Used . . . . . . . . . . . . . . 4

B Comparison of Full Two-plate and Outer-half-space Simulations . . . . . . 4

C Effect of Tilting the Divertor Plate ............... 5

D Helium Simulations . . . . . . . . . . . . . . 5 .

$\mathrm{E}$ Neon Simulations $\ldots \ldots \ldots \ldots \ldots \ldots \ldots \ldots$

IV Summary and Conclusions $\quad \because \quad 7$

A Plasma/Neutral Fluid Equations Used in UEDGE . . . 9

\section{Introduction}

The ITER divertor concept has evolved some over the last couple of years, ${ }^{1-3}$ but maintains a strong reliance on injection of moderate- $\mathrm{Z}$ impurities to radiate a significant portion of the energy crossing the.magnetic separatrix before it strikes the divertor plate. The heat flux which does strike the plate is further reduced by tilting the plate. Thus, it is important to include and understand the effects of both of these elements for the divertor design.

To do this study, we use the UEDGE code which is a fully implicit, 2-D edge/SOL transport code developed over the last five years. ${ }^{5-9}$ It solves the classical Braginskii ${ }^{4}$ transport equations for plasma transport along the magnetic field, B, and assumes anomalous diffusive transport across $B$. The neutral gas that recycles from the divertor plate is modeled by fluid equations where inertia is retained in the parallel direction along $\mathbf{B} .^{11}$ In comparisons with a more complete Navier-Stokes neutral gas model in a slab version of UEDGE, ${ }^{10}$ 
this reduced Navier-Stokes model has been shown to accurately represent the ion-neutral momentum exchange and the collisionally enhanced momentum and energy transport including neutral-neutral collisions. The nonorthogonal mesh algorithm in UEDGE makes use of a general 9-point difference stencil which preserves the magnetic flux surfaces as one coordinate to resolve the highly anisotropic transport along and across $\mathbf{B} .^{8}$ The parallel transport of the multi-charge state impurities is described by force-balance equations ${ }^{8}$ using the trace-level coefficients presented earlier ${ }^{12,13}$ or by the FMOMBAL package. ${ }^{14}$ Atomic data for hydrogen rates of excitation, ionization, and recombination by electrons is taken from the work of Stotler, ${ }^{15}$ and the impurity rates are from STRAHL ${ }^{16}$ via a B2.5 package by Braams. ${ }^{17}$

\section{Geometry and Equations}

We use the MHD equilibrium provided by A. Kukushkin of the Joint Central Team in 1994 as the standard ITER case for divertor benchmarking. The full single-null flux surfaces for the edge/SOL region and the associated orthogonal mesh are shown in Fig. 1. With the poloidal magnetic flux, $\psi$, normalized to unity on the separatrix, we generally include the region out to $\psi=1.04$, and place the core and private flux boundaries at $\psi=0.992$ as shown. Some of the calculations are done considering only the outer half of the SOL as shown by dotted lines in Fig. 1. A nonorthogonal mesh is used for cases where the divertor plate is tilted; such tilting significantly affects only the region close to the plate because of the long divertor leg. In Fig. 2, we show the outer divertor plate region of a nonorthogonal mesh with tilt angle $\theta_{t}=45^{\circ}$ between the normal to the flux surface and the plate.

The mesh that we typically use to do most calculations is 72 poloidal points for a full mesh ( 36 for the outer-half calculations) and 16 radial mesh points. We have checked the sensitivity of some of the results by doubling the poloidal or radial number; we have not found any cases that are sensitive to an increased number of points. We also use a closely spaced poloidal mesh near the divertor plates with a minimum cell size of $0.05 \mathrm{~cm}$ for the standard mesh; such small cell sizes are needed to resolve the ionization layer of the gas at the plates.

As mentioned in the Introduction, we use fluid equations to describe both the plasma 
and the neutrals. The plasma and neutral densities are typically quite large $\left(\sim 10^{21} \mathrm{~m}^{-3}\right)$ near the plate such that the mean free path is short enough to justify a fluid treatment. To avoid filling the main part of the report with too much detail, we defer the full description of the equations to the Appendix.

\section{Results of ITER Simulations}

\section{A. Parameters and Coefficients Used}

We consider two cases for the anomalous diffusion coefficients, one having $D=0.33 \mathrm{~m}^{2} / \mathrm{s}$ and $\chi_{e, i}=0.5 \mathrm{~m}^{2} / \mathrm{s}$ and the second has twice these values. The core density for the hydrogen is in the range $3-5 \times 10^{19} \mathrm{~m}^{-3}$. We use flux-limits on the ion and electron heat fluxes that correspond to 0.15 times the thermal flux, $n v_{t} T$, where $v_{t} \equiv(2 T / m)^{1 / 2}{ }^{18}$. The recycling at the divertor plate is taken to be unity for hydrogen and for impurities. For most of the runs, there is no pumping on the side walls of gas or plasma, although we will show the effect of pumping gas on the private flux boundary. The density of impurities, helium and neon, are controlled by fixing the level on the core boundary of $\mathrm{He}^{2+}$ or $\mathrm{Ne}^{8+}$. The power crossing the core boundary is $75 \mathrm{MW}$ in each of the electron and ion channels for the full single-null (total of $150 \mathrm{MW}$ ) and $50 \mathrm{MW}$ in each channel for the outer SOL only (total of $100 \mathrm{MW}$ ). The outer SOL plasma parameters for these two cases are similar, as we shall show that there is roughly twice as much power flowing to the outer as the inner plate.

\section{B. Comparison of Full Two-plate and Outer-half-space Simulations}

Divertor plate plasma parameters from full two-plate simulations for two different sets of diffusion coefficients are given in tables I and II. The outboard:inboard power split is about $2: 1$ in both cases. This observation is the basis for setting the power into the SOL at $100 \mathrm{MW}$ in the outer-half-space simulations. Results from an outer-half-space simulation with weak radial diffusion (as in table I) are given in table III. A comparison of the plasma parameters in tables I and III indicates that the outer-half-space simulation significantly overestimates the peak electron temperature at the outer divertor plate, but other plasma parameters are in good agreement with the full two-plate simulations. Orthogonal divertor 
plates were used for these simulations.

\section{Effect of Tilting the Divertor Plate}

Divertor plasma parameters are strongly affected by the orientation of the divertor plate as shown in Figures 3,4 and 5. As the plate is tilted away from the orthogonal position, Figure 3 shows that the plasma temperature near the outer wall increases due to reduced local recycling. Neutrals that originate near the outer wall are directed across flux surfaces toward the separatrix where they are ionized, causing an increase in the ion density near the separatrix strike point as shown in Figure 4. The peak heat flux at the divertor plate decreases with increasing tilt angle because the total heat flux is spread out over a larger area. However, as shown in Figure 5 for tilt angles larger than about $45^{\circ}$ the decrease in peak heat flux appears to be less than expected from purely geometrical considerations. For the orthogonal plate, the electron component contributes about $75 \%$ of the total, but for

the strongly tilted plate, all three components (electron, ion and recombination) contribute equally. Impurities and their associated radiation are also strongly affected by the tilt angle, as discussed in the following sections.

\section{Helium Simulations}

Figure 6 shows how plasma parameters vary with core helium concentration over the range 0-15 percent. The total helium radiation is $12 \mathrm{MW}$ for 15 percent core helium concentration. The hydrogenic radiation is about $13 \mathrm{MW}$, nearly independent of the helium concentration. Total power crossing the core boundary is $150 \mathrm{MW}$, so the total radiated power is less than $17 \%$ of the power into the SOL. This is a full two-plate simulation with orthogonal divertor plates and core hydrogenic density $4 \times 10^{19} \mathrm{~m}^{-3}$. Weak values of the radial diffusion coefficients are used. A simple diffusive neutrals model is used for both hydrogen and helium neutrals.

Simulations in an outer-half-space configuration show that the plasma is strongly affected by plate tilt. Figure 7 shows that the plate tilt tends to increase the hydrogenic ion density in the private flux region near the plate. Figure 8 shows that for one percent helium concentration at the core boundary, the helium concentration in the divertor is only 
0.001 percent near an orthogonal plate, but this increases to about one percent for a modest plate tilt (about $\theta_{t}=45^{\circ}$ ). The helium concentration is largest (about 3 percent) at the outer wall near the tilted plate. With the tilted plate there are strong particle flows (orders of magnitude larger than for an orthogonal plate) of both hydrogen and helium along the outer boundary of the plasma toward the divertor plate and corresponding flows away from the divertor plate along the separatrix (see Figure 9). The ion thermal force on the helium impurity is included in these simulations. The inertial model is used for neutral hydrogen. Power crossing the core boundary is $50 \mathrm{MW}$ per channel and the core hydrogen density is $3 \times 10^{19} \mathrm{~m}^{-3}$ with weak values of the radial diffusion coefficients.

We have simulated the effect of pumping by setting the albedo less than unity on a $10 \mathrm{~cm}$ section of the private flux wall near the outboard divertor plate. Figure 10 shows that with increasing pumping the plate electron temperature approximately doubles as the hydrogenic particle removal rate reaches $8 \mathrm{kA}$. Over this range of pumping strength the peak heat flux on the divertor plate increased by less than 20 percent. For these simulations the helium concentration at the core boundary was 1 percent, but very little helium was pumped (about $1 \mathrm{Amp}$ at the maximum pump rate) because the helium concentration is low in the private flux region (see Figure 8). The pumping would be effective in removing helium if the active pump area is on the outer wall where the helium concentration is much larger.

\section{E. Neon Simulations}

The strength of the radial diffusion for the impurity ions has a strong effect on the total radiated power and the radiation pattern as shown in Figure 11. For weak diffusion, the radiation above and below the $\mathrm{x}$-point is about equal, whereas for strong diffusion the radiation occurs mostly above the $\mathrm{x}$-point. Table IV shows the variation of the total radiated power with the strength of the radial diffusion for several hydrogenic and neon densities at the core boundary. For 0.2 percent neon at the core boundary and $5 \times 10^{19} \mathrm{~m}^{-3}$ core hydrogen density, the total neon radiation decreases from $6.1 \mathrm{MW}$ with weak radial diffusion to $3.4 \mathrm{MW}$ with strong radial diffusion. The hydrogenic radiation does not change significantly. The most strongly radiating case yields $25 \dot{M} W$ of neon radiation for weak radial diffusion with core hydrogen density $3 \times 10^{19} \mathrm{~m}^{-3}$ and 1.0 percent neon. 
The tilt angle of the divertor plate dramatically changes the distribution of the impurities and total radiated power. This is illustrated for simulations with a relatively low 0.2 percent neon at the core boundary as shown in Figures 12 and 13. For the orthogonal plate the total neon radiation is $3.8 \mathrm{MW}$, but this increases to $5.9 \mathrm{MW}$ for even a modest tilt angle $\left(\theta_{t}=25^{\circ}\right)$. The tilted plate induces strong plasma flows in the SOL which distibute the impurities more uniformly over the length of the divertor leg. For the orthogonal plate most of the radiation occurs above the $\mathrm{x}$-point, but with the tilted plate the radiation in the divertor leg is comparable to that above the $\mathrm{x}$-point.

The importance of the ion thermal force on the impurities is illustrated in Figures 14 and 15 which compare the radiation pattern and impurity density for cases with and without the ion thermal force term in the impurity force balance equation. These examples use a Iow concentration ( 0.001 ) of neon at the core boundary, but similar behaviour is expected at higher concentrations. In the absence of the ion thermal force the impurity density and radiation extend well below the $\mathrm{x}$-point into the divertor region, with the radiation peaking locally in a weak marfe-like structure in the private flux region just below the $x$-point; the total impurity radiation in this case is $7.5 \mathrm{MW}$. With the thermal force activated, the impurities and associated radiation are confined to the SOL region above the $x$-point; the total impurity radiation is only 1.9 MW. These simulations used strong radial diffusion coefficients.

\section{Summary and Conclusions}

We have observed that the magnitude and spatial distribution of impurities (helium and/or neon) and associated radiation are sensitive to the plate tilt angle, radial diffusion strength, and ion thermal force. For orthogonal plates the impurity concentration is low everywhere in the divertor compared to the core boundary value, whereas for tilted plates the impurity concentration at the outer wall near the plate may exceed the core boundary value. For weak radial diffusion the impurities are distributed relatively uniformly above and below the $\mathrm{x}$-point to the divertor plate, whereas for strong diffusion the impurities do not penetrate significantly into the divertor region below the $\mathrm{x}$-point. The ion thermal force also tends to keep the impurities above the $x$-point and out of the divertor region. 
The helium concentration is highest at the outer wall near a tilted divertor plate with weak radial diffusion. The maximum concentration may be several times the value at the core boundary. The helium concentration on the private flux wall is typically an order of magnitude lower. Helium radiation losses are, at most, comparable to the hydrogenic radiation (of order $10 \mathrm{MW}$ ) for core helium concentrations up to 15 percent.

For helium removal, pumping on the private flux wall near the divertor plates does not appear to be very effective. The helium concentration is much larger at the outer wall. Peak temperatures at the divertor plate may increase by up to a factor of two for strong pumping.

Our most strongly radiating plasma has $25 \mathrm{MW}$ of neon radiation losses compared to $100 \mathrm{Mw}$ of total power into the outer half of the SOL with 1 percent neon concentration at the core boundary and an orthogonal divertor plate. Simulation results at lower neon concentrations indicate that the neon radiation losses will be significantly larger for tilted plates.

Acknowledgments: Work performed under the auspices of the United States Department of Eriergy by the Lawrence Livermore National Laboratory under contract number W-7405ENG-48. 


\section{Appendix A. Plasma/Neutral Fluid Equations Used in UEDGE}

The basic equations are written in the $(x, y)$ poloidal and radial coordinates (suppressing the metric factors). The plasma continuity equations for ion species $j$ is,

$$
\begin{aligned}
\frac{\partial n_{j}}{\partial t}+\frac{\partial n_{j} v_{j x}}{\partial x}+\frac{\partial n_{j} v_{j y}}{\partial y}=\left(K_{j-1}^{i} n_{j-1}\right. & \left.+K_{j+1}^{r} n_{j+1}\right) n_{e}-\left(K_{j}^{i}+K_{j}^{r}\right) n_{j} n_{e} \\
& -K_{j}^{c x} n_{j} n_{g h}+\delta_{j, h} \sum_{k} K_{k}^{c x} n_{k} n_{g h}
\end{aligned}
$$

where $K^{r i}, K^{r}$, and $K^{c x}$ are rate coefficients $\left(\left\langle\sigma v_{e}\right\rangle\right)$ for ionization, recombination, and charge exchange, respectively, $n_{g h}$ is the density of the hydrogenic species, and $\delta_{j, h}$ is the Kronecker delta with $j=h$ corresponding to the hydrogenic species.

The ion parallel momentum equation,

$$
\begin{array}{r}
\frac{\partial}{\partial t}\left(m_{j} n_{j} v_{j \|}\right)+\frac{\partial}{\partial x}\left(m_{j} n_{j} v_{j \|} v_{j x}-\eta_{j x} \frac{\partial v_{j \|}}{\partial x}\right)+\frac{\partial}{\partial y}\left(m_{j} n_{j} v_{j \|} v_{j y}-\eta_{j y} \frac{\partial v_{j \|}}{\partial y}\right) \\
: \quad: \quad=\frac{B_{x}}{B}\left(-\frac{\partial p_{j}}{\partial x}\right)-e Z_{j} n_{j} \frac{\partial \Phi}{\partial x}+\mathcal{F}_{j}+\mathcal{A}_{j}+\delta_{j, h} F_{j n}+S_{m v_{\|}}
\end{array}
$$

where $B_{x} / B$ is the ratio of the poloidal to total magnetic field and $\Phi$ is electrostatic potential. The Coulomb interaction force between all charged species is represented by $\mathcal{F}$. The term $\mathcal{A}$ denotes the effects of atomic processes of ionization, recombination, and charge exchange which cause a local exchange of momentum between neighboring charge states with different $v_{j \| l} \cdot \dot{\text { In }}$ the trace-limit case, $\mathcal{F}$ can be expressed as gradients of ion and electron temperatures (thermal forces) and relative drift velocities of the different species using specific coefficients [13-14]. In this limit, the ion inertia and viscosity are only retained for the hydrogenic species, whereas for the impurities, the terms retained are the thermal forces, friction, pressure gradient, and electric field, giving an algebraic equation for the impurity parallel velocities. ${ }^{8}$ For the non-trace case, all of the momentum equations, including that for the electrons, are added, and solved for the density mass-averaged velocity. This velocity, together with the plasma parameters and their gradients are then used as input to the package FMOMBAL developed by Hirshman ${ }^{14}$ to calculate the parallel impurity velocities and the friction forces for all species. The ion-neutral friction term $F_{h n}$, is given by

$$
F_{h n}=m n_{g h} n_{h} K_{h}^{c x}\left(v_{n \|}-v_{h \|}\right)-m n_{e}\left(n_{h} K_{h}^{r} v_{h \|}-n_{n} K_{h}^{i} v_{n \|}\right)
$$

where this term is presently only nonzero for the hydrogenic ions $(j=h)$. The poloidal ion 
velocities are

$$
v_{j x}=\frac{B_{x}}{B} v_{j \|}
$$

and the radial velocity is

$$
v_{j y}=-\frac{D_{j} a}{n_{j}} \frac{\partial n_{j}}{\partial y}
$$

where $D_{j a}$ is the anomalous density diffusion coefficient for the $j^{\text {th }}$ species. A constant radial velocity or pinch term can also be included, but here is taken to be zero. The electron velocity is

$$
\mathbf{v}_{e}=\frac{n_{j} Z_{j} \mathbf{v}_{j}}{n_{e}}-\frac{\mathbf{J}}{e n_{e}}
$$

For the cases presented in this report, we take the current, $\mathbf{J}$, to be zero.

The electron thermal energy equation is

$$
\begin{aligned}
\frac{\partial}{\partial t}\left(\frac{3}{2} n_{e} T_{e}\right)+\frac{\partial}{\partial x}\left(\frac{5}{2} n_{e} v_{e x} T_{e}-\kappa_{e x}\right. & \left.\frac{\partial T_{e}}{\partial x}-\alpha n_{e} T_{e} \frac{B_{x}}{B} \frac{J_{\|}}{e n_{e}}\right)+\frac{\partial}{\partial y}\left(\frac{5}{2} n_{e} v_{e y} T_{e}-\kappa_{e y} \frac{\partial T_{e}}{\partial y}\right) \\
& =v_{j x} \frac{\partial p_{e}}{\partial x}-v_{h y} \frac{\partial p_{h}}{\partial y}+\mathrm{E} \cdot \mathrm{J}-K_{q}\left(T_{e}-T_{i}\right)+S_{E e}
\end{aligned}
$$

Here the conductivity in the radial direction is taken as anomalous for both electrons and ions, with $\kappa_{e y, i y} \equiv \chi_{e, i}$.

The ion thermal energy equation is obtained by summing the the equations for all ion species, including neutrals under the assumption that they share a common temperature, i.e., $T_{j}=T_{n} \equiv T_{i}$.

$$
\begin{gathered}
\sum_{j}\left[\frac{\partial}{\partial t}\left(\frac{3}{2} n_{j} T_{i}\right)+\frac{\partial}{\partial x}\left(\frac{5}{2} n_{j} v_{j x} T_{i}-\kappa_{j x} \frac{\partial T_{i}}{\partial x}\right)+\frac{\partial}{\partial y}\left(\frac{5}{2} n_{i} v_{j y} T_{i}-\kappa_{j y} \frac{\partial T_{i}}{\partial y}\right)\right] \\
=\sum_{j}\left[v_{j x} \frac{\partial p_{j}}{\partial x}+v_{j y} \frac{\partial p_{j}}{\partial y}+\eta_{j x}\left(\frac{\partial v_{j \|}}{\partial x}\right)^{2}+\eta_{j y}\left(\frac{\partial v_{j \|}}{\partial y}\right)^{2}+K_{j q}\left(T_{e}-T_{i}\right)+\frac{1}{2} m_{j} v_{j \|}^{2} K_{j}^{i} n_{j} n_{e}+S_{E i}\right] .
\end{gathered}
$$

The hydrogen and impurity neutrals are described by separate continuity equations of the form

$$
\frac{\partial n_{g}}{\partial t}+\frac{\partial n_{g} v_{g x}}{\partial x}+\frac{\partial n_{g} v_{g y}}{\partial y}=S_{g}
$$

The neutral parallel momentum equation for hydrogen is

$$
\frac{\partial}{\partial t}\left(m n_{n} v_{n \|}\right)+\frac{\partial}{\partial x}\left(m n_{n} v_{n x} v_{n \|}-\eta_{n x} \frac{\partial v_{n \|}}{\partial x}\right)+\frac{\partial}{\partial y}\left(m n_{n} v_{n y} v_{n \|}-\eta_{n y} \frac{\partial v_{n \|}}{\partial y}\right)
$$




$$
=-\frac{B_{x}}{B} \frac{\partial P_{n}}{\partial x}-F_{h n}
$$

The neutral pressure is $P_{n}$, and $\eta$ is the viscosity. The hydrogen velocities in the two directions perpendicular to the magnetic field are given by a diffusion equation obtained from assuming the dominance of collisions in these directions:

$$
\mathrm{v}_{\perp g}=-\frac{\nabla\left(n_{g} T_{i}\right)}{m_{z} n_{g} n_{z} K_{g}^{m}}
$$

where $K_{g}^{m}$ is a momentum rate coefficient which for hydrogen is mainly due to charge exchange. For the impurities, the poloidal and radial velocities both come entirely from a diffusion equation as given by Eq. (A12). 


\section{References}

${ }^{1}$ G. Janeschitz, K. Borass, G. Federici, Y. Igitkhanov, A. Kukushkin, H.D. Pacher, G.W. Pacher, and M. Sugihara, J. Nucl. Mat. 220-222, 73 (1995).

${ }^{2}$ R.R. Parker, "Plasma-Wall Iteractions for ITER," presented at the $12^{\text {th }}$ International Conf. Plasma Surface Interactions Contr. Fusion Devices, Saint Raphael, France May 20-24, 1996; to be pub. in J. Nucl. Mat.

${ }^{3}$ D.E. Post, B. Braams, J. Mandrekas, N. Putvinskaya, M. Rensink, T. Rognlien, W. Stacey, and F. Wising, "Power Balance in the ITER Plasma and Divertor," presented at the $12^{\text {th }}$ International Conf. Plasma Surface Interactions Contr. Fusion Devices, Saint Raphael, France May 20-24, 1996; to be pub. in J. Nucl. Mat.

${ }^{4}$ S.I. Braginskii, Transport processes in a plasma Reviews of Plasma Physics, Vol. I, Ed. M.A. Leontovich (Consultants Bureau, New York, 1965), p. 205.

${ }^{5}$ T.D. Rognlien, J.L. Milovich, M.E. Rensink, and G.D. Porter, J. Nucl. Mat. 196-198, 347 (1992).

${ }^{6}$ D.A. Knoll; A.K. Prinja, and R.B. Campbell, J. Comp. Phys. 104, 418 (1992).

${ }^{7}$ T.D. Rognlien, P.N. Brown, R.B. Campbell, T.B. Kaiser, D.A. Knoll, P.R.McHugh, G.D. Porter, M.E. Rensink, and G.R. Smith, Contrib. Plasma Phys. 34, 362 (1994).

${ }^{8}$ G.R. Smith, P.N. Brown, R.B. Campbell, D.A. Knoll, P.R. McHugh, M.E. Rensink, and . T.D. Rognlien, J. Nucl. Mat. 220-222, 1024 (1995).

${ }^{9}$ T.D. Rognlien, B.J. Braams, and D.A. Knoll, Contrib. Plasma Phys. 36, 105 (1996).

${ }^{10}$ D.A. Knoll, P.R. McHugh, S.I. Krasheninnikov, and D.J. Sigmar, Phys. Plasmas 3, 293 (1996).

${ }^{11}$ F. Wising, D.A. Knoll, S.I. Krasheninnikov, and T.D. Rognlien, Contr. Plasma Phys. 36, 309 (1996).

${ }^{12}$ Yu.L. Igitkhanov, Contrib. Plasma Phys. 28, 477 (1988).

${ }^{13}$ M. Keilhacker, R. Simonini, A. Taroni, and M.L. Watkins, Nucl. Fusion 31, 535 (1991). 
${ }^{14}$ S.P. Hirshman, private communication, 1995; base on work in S.P. Hirshman and D.J. Sigmar, Nucl. Fusion 21, 1079 (1981).

${ }^{15}$ D.P. Stotler, private communication, 1995 ; based on work initiated in D.P. Stotler, D.E. Post, and D. Reiter, Bull. Am. Phys. Soc. 38, 1919 (1993).

${ }^{16} \mathrm{~K}$. Behringer, "Description of the Impurity Transport Code STRAHL," JET Report $R(87) 08$ (1987).

${ }^{17}$ B.J. Braams, impurity rate tables for B2.5 code, available from CFS storage facility on the NERSC computer system, 1995.

${ }^{18}$ R.H. Cohen and T.D. Rognlien, Contr. Plasma Phys. 34, 198 (1994).

${ }^{19}$ G.D. Porter, et al., Phys. Plasmas 3, 1967 (1996). 


\section{Figures}

FIG. 1. The ITER magnetic flux surfaces and the resulting mesh (with reduced number of mesh points) for the full single-null simulations with orthogonal plates. The region to the right of the dashed line is that included in the outer-half SOL calculations; symmetry boundary conditions are then applied where the dashed line intersects the full mesh.

FIG. 2. The outer divertor plate region showing the orientation and specification for a tilted plate.

FIG. 3. Electron temperature profiles at the outer divertor for various plate tilt angles. Half-space simulation with no impurities.

FIG. 4. Ion density profiles at the outer divertor for various plate tilt angles. Half-space . simulation with no impurities.

FIG. 5. Peak power at the outer divertor plate depends on the plate tilt angle. Half-space simulation with no impurities.

FIG. 6. Variation of total hydrogenic and helium radiated power and peak plate electron temperatures with helium core concentration for orthagonal plate configuration.

FIG. 7. Contours of hydrogenic ion density in the outboard divertor leg for orthogonal and tilted plate configurations. The hydrogenic ion density at the core boundary is $3 \times 10^{19} \mathrm{~m}^{-3}$.

FIG. 8. Contours of total (ions plus neutrals) helium concentration, $\mathrm{n}_{\mathrm{He}} / \mathrm{n}_{\mathrm{e}}$, in the outboard divertor leg for orthogonal and tilted plate configurations. The helium concentration is 0.013 at the core boundary.

FIG. 9. Total (ions plus neutrals) helium particle flux in the outboard divertor leg for orthogonal and tilted plate configurations. The vector length varies as the square root of the particle flux. The maximum absolute values are of order $10^{3} \mathrm{~m}^{-2} \mathrm{sec}^{-1}$ for the orthogonal plate and $10^{10} \mathrm{~m}^{-2} \mathrm{sec}^{-1}$ for the tilted plate.

FIG. 10. Variation of peak plate electron temperature and hydrogenic ion removal with pump strength (1-albedo) on a $10 \mathrm{~cm}$ section of the private flux wall near the outer 
divertor plate. Helium concentration at the core boundary was 1 percent with weak radial diffusion coefficients.

FIG. 11. Contours of neon radiation in the outer SOL for cases with weak and strong radial diffusion. The hydrogenic ion density at the core boundary is $5 \times 10^{19} \mathrm{~m}^{-3}$ with 0.2 percent neon.

FIG. 12. Contours of neon concentration in the outer SOL for orthogonal and moderately tilted plate. The neon concentration at the core boundary is 0.2 percent.

FIG. 13. Contours of neon radiation in the outer SOL for orthogonal and moderately tilted plate. The neon concentration at the core boundary is 0.2 percent. Total neon radiation is $3.8 \mathrm{MW}$ for orthogonal and $5.9 \mathrm{MW}$ for tilted plate.

FIG. 14. Contours of neon radiation in the outer SOL for cases with and without the ion thermal force in the impurity force balance equation. Both cases use strong radial diffusion with 0.001 neon concentration at the core boundary.

FIG. 15. Contours of total (ions plus neutrals) neon density in the outer SOL for cases with and without the ion thermal force in the impurity force balance equation. Both cases use strong radial diffusion with 0.001 neon concentration at the core boundary. 
Tables

TABLE I. Divertor plate parameters for full two-plate simulation with $150 \mathrm{MW}$ into the SOL and weak radial diffusion.

TABLE II. Divertor plate parameters for full two-plate simulation with $150 \mathrm{MW}$ into the SOL and strong radial diffusion.

TABLE III. Divertor plate parameters for outer-half-space simulation with $100 \mathrm{MW}$ into the SOL and weak radial diffusion.

TABLE IV. Radiated power for weak and strong radial diffusion at various hydrogenic and neon core boundary densities. 


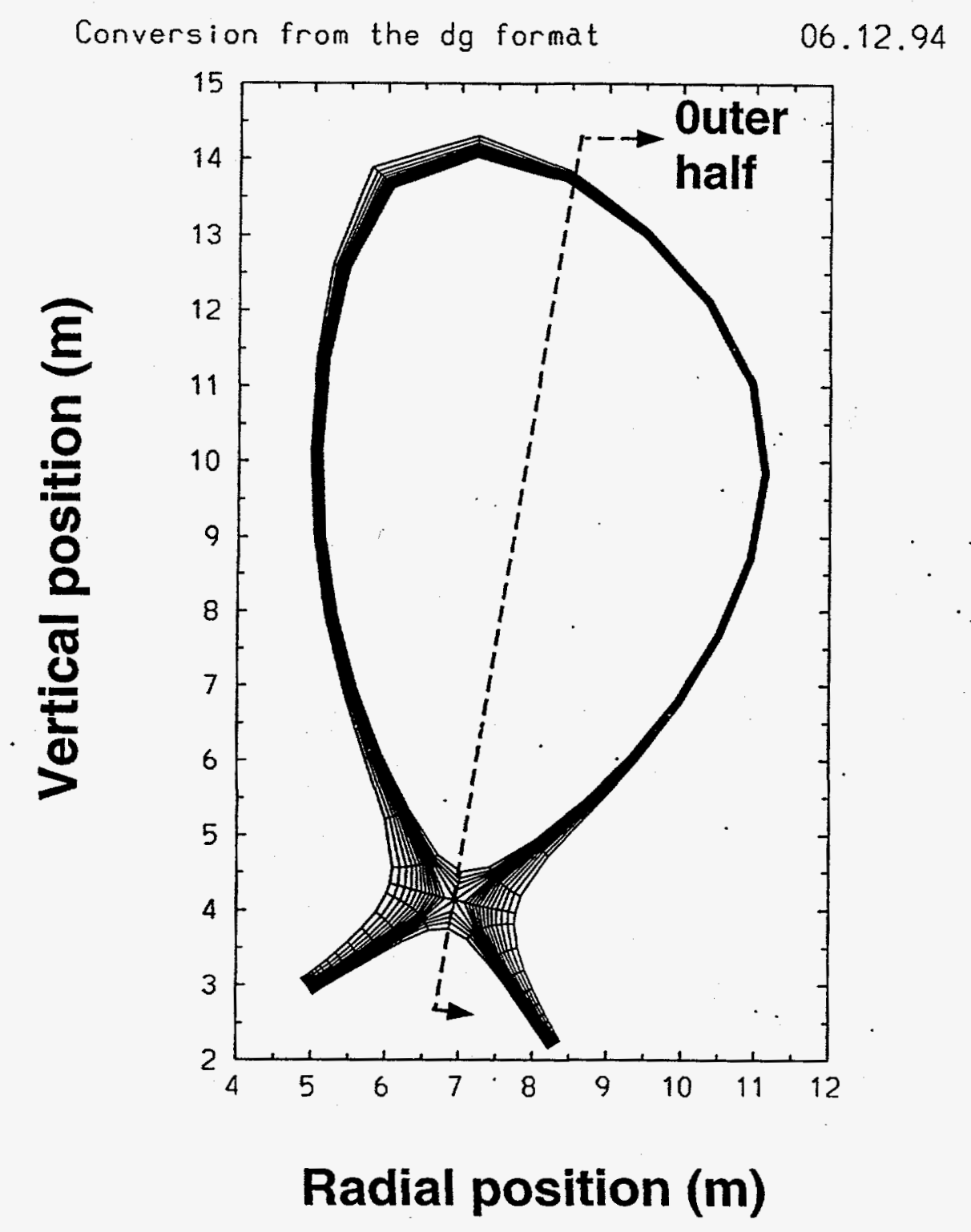

$$
\begin{aligned}
& \text { iIter/Figs. } \\
& \sim \text { rognlian/Tex/Report/ umesh1.id }
\end{aligned}
$$




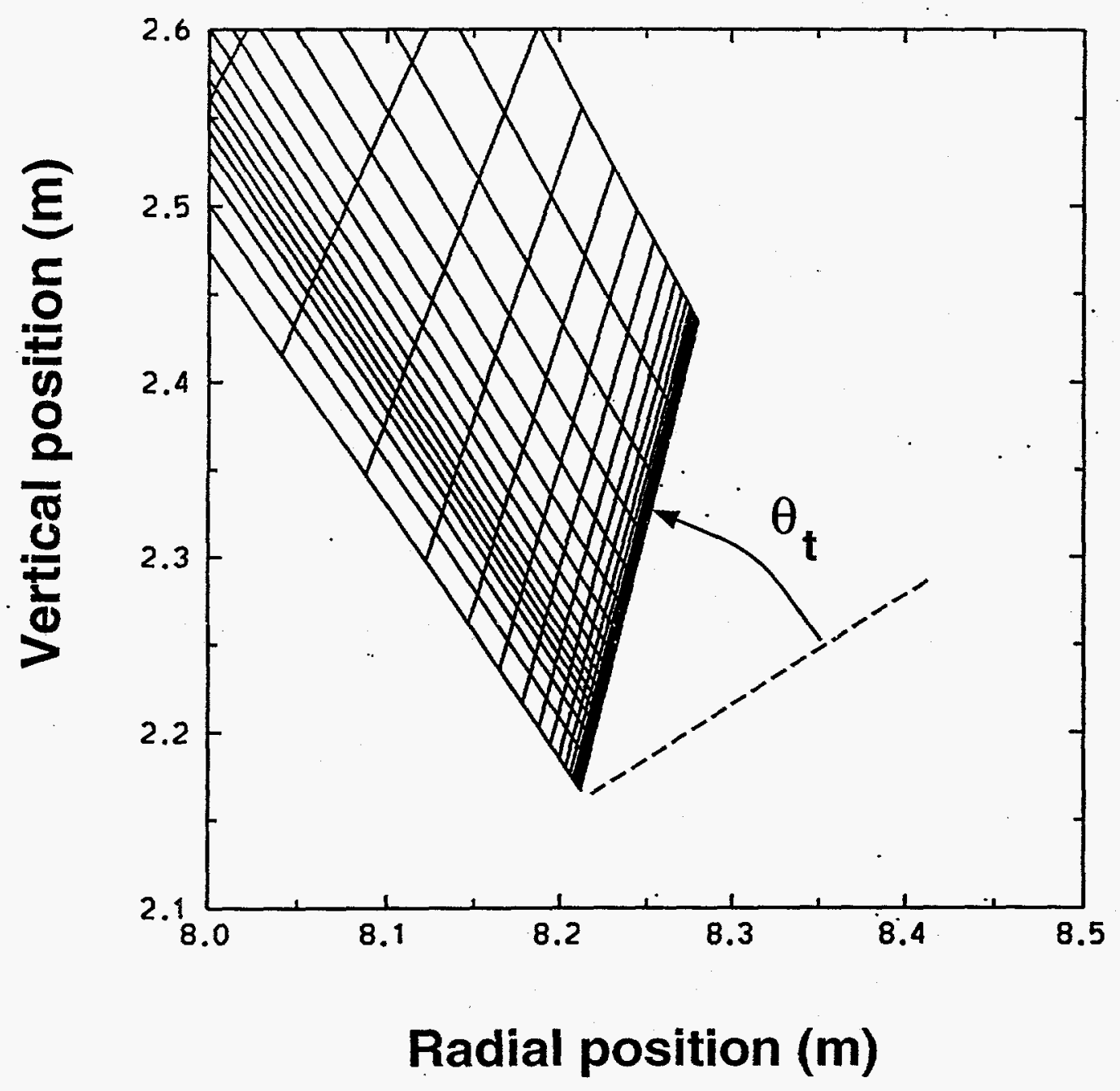

mesh4a2.id 


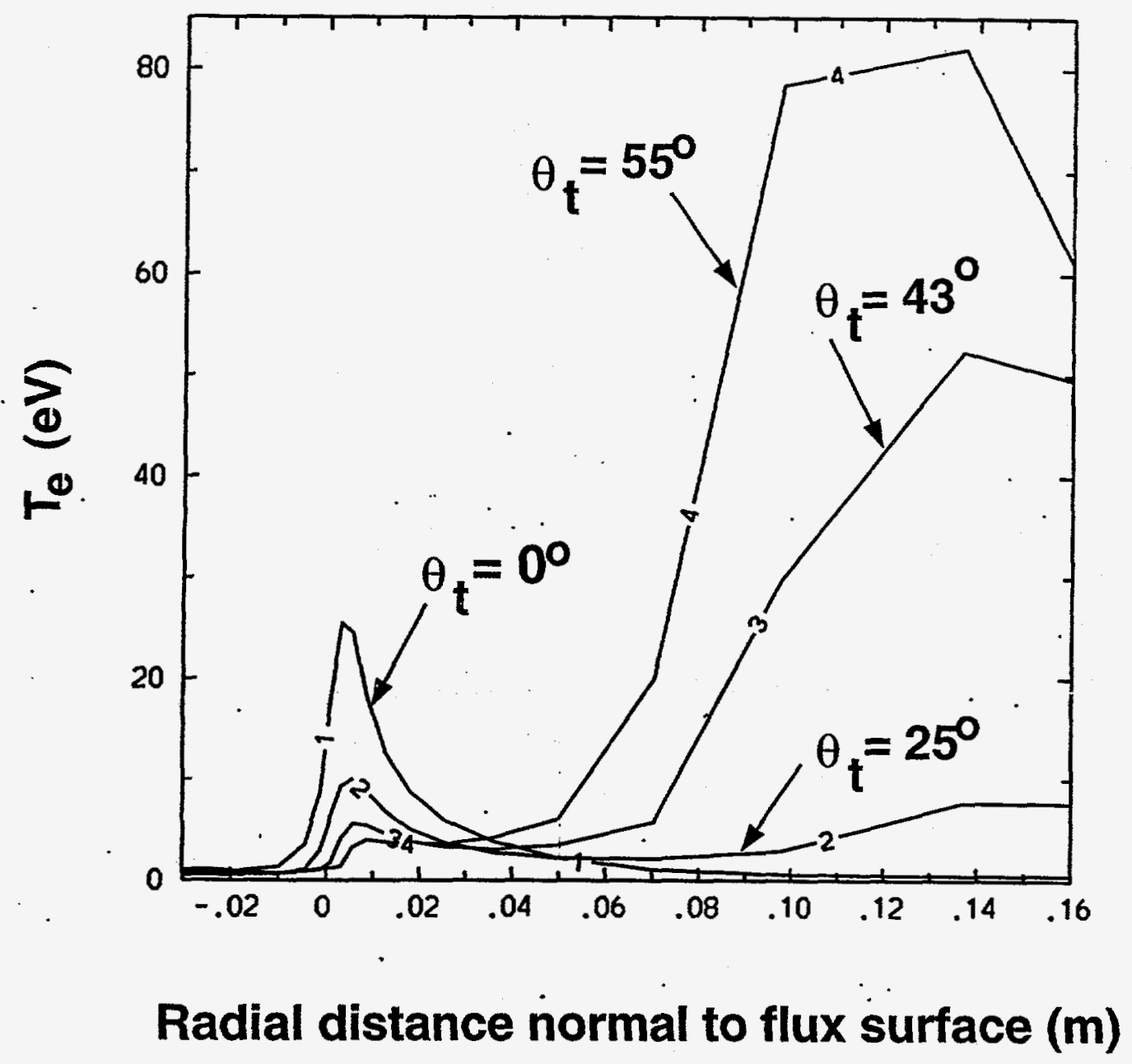

teprofid 


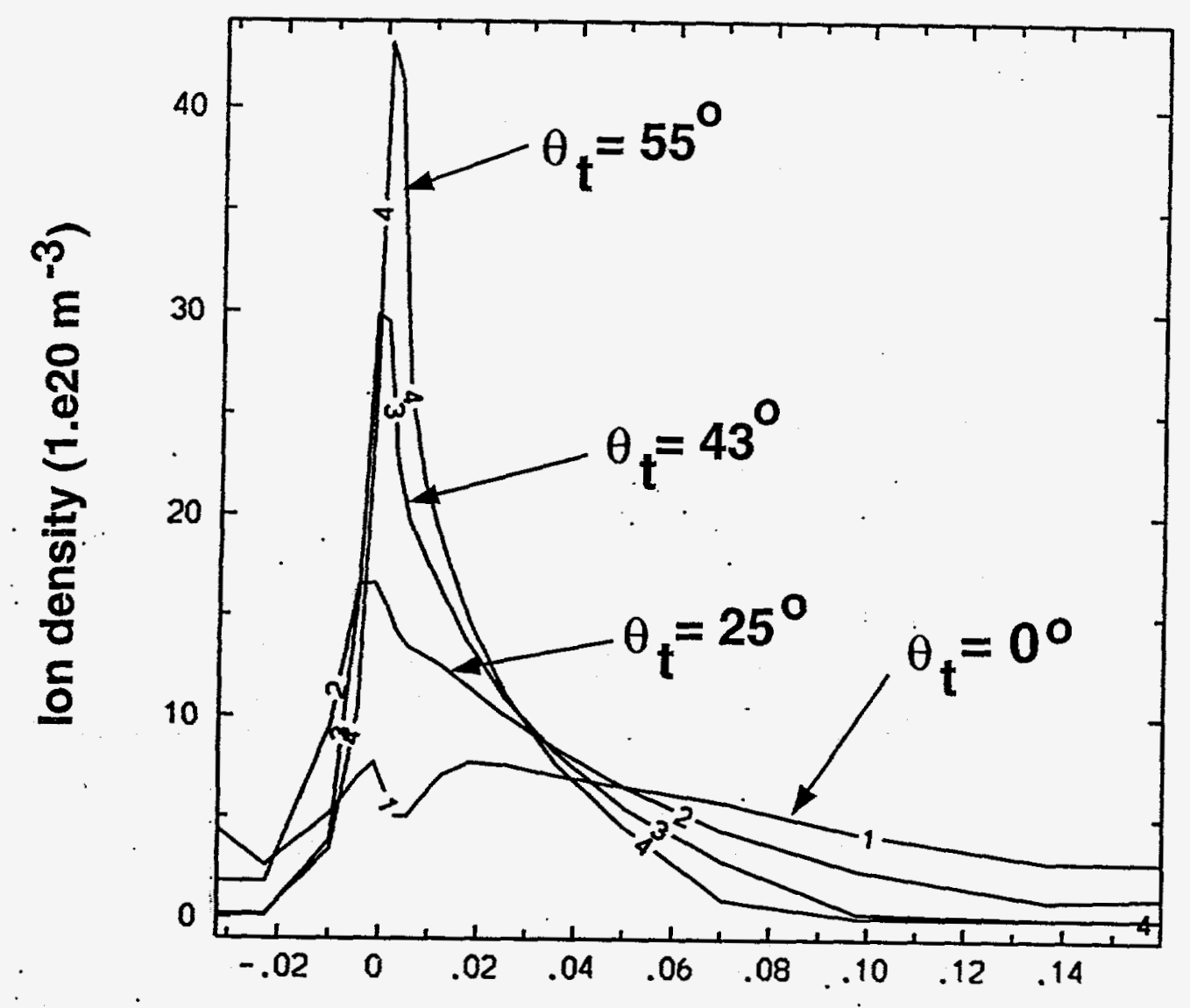

Radial distance normal to flux surface (m) 


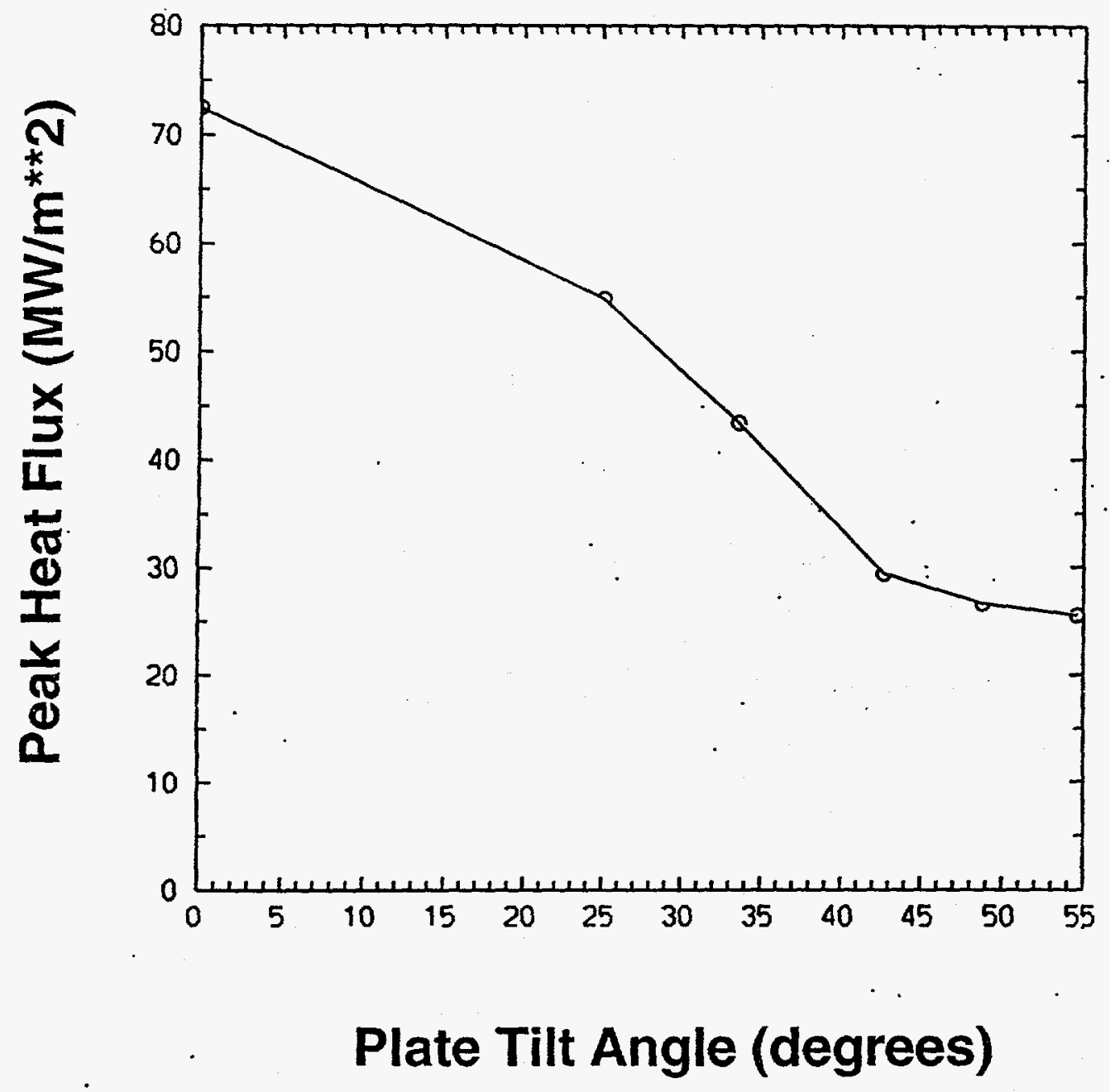

phat_tilt.id 


\section{Radiated Power (MW)}

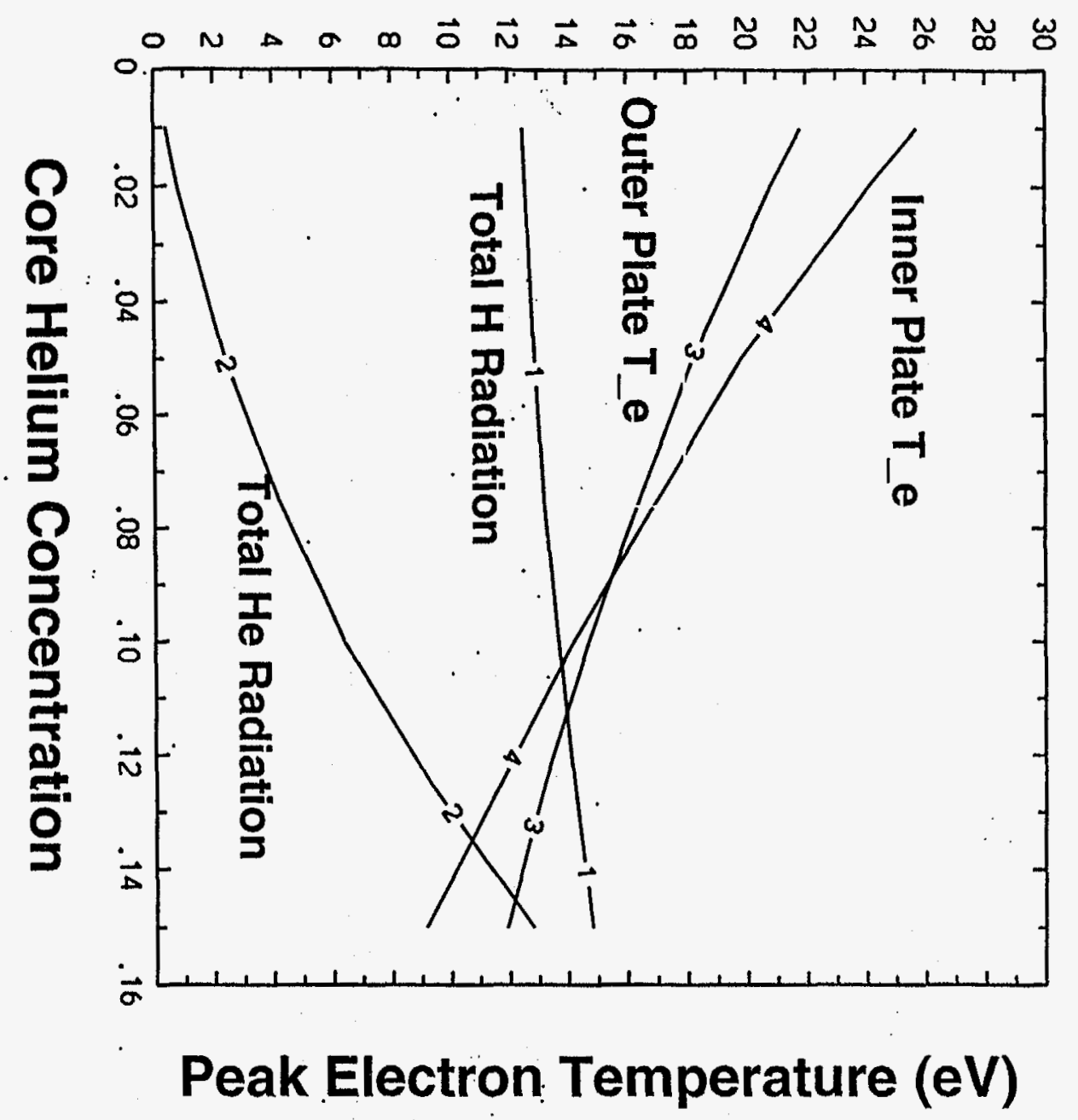




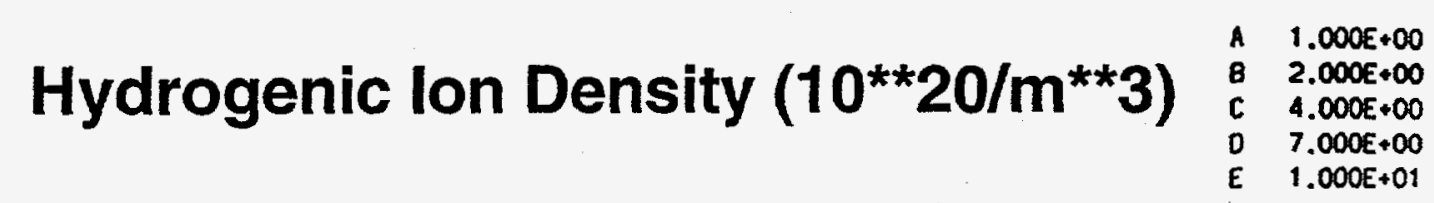

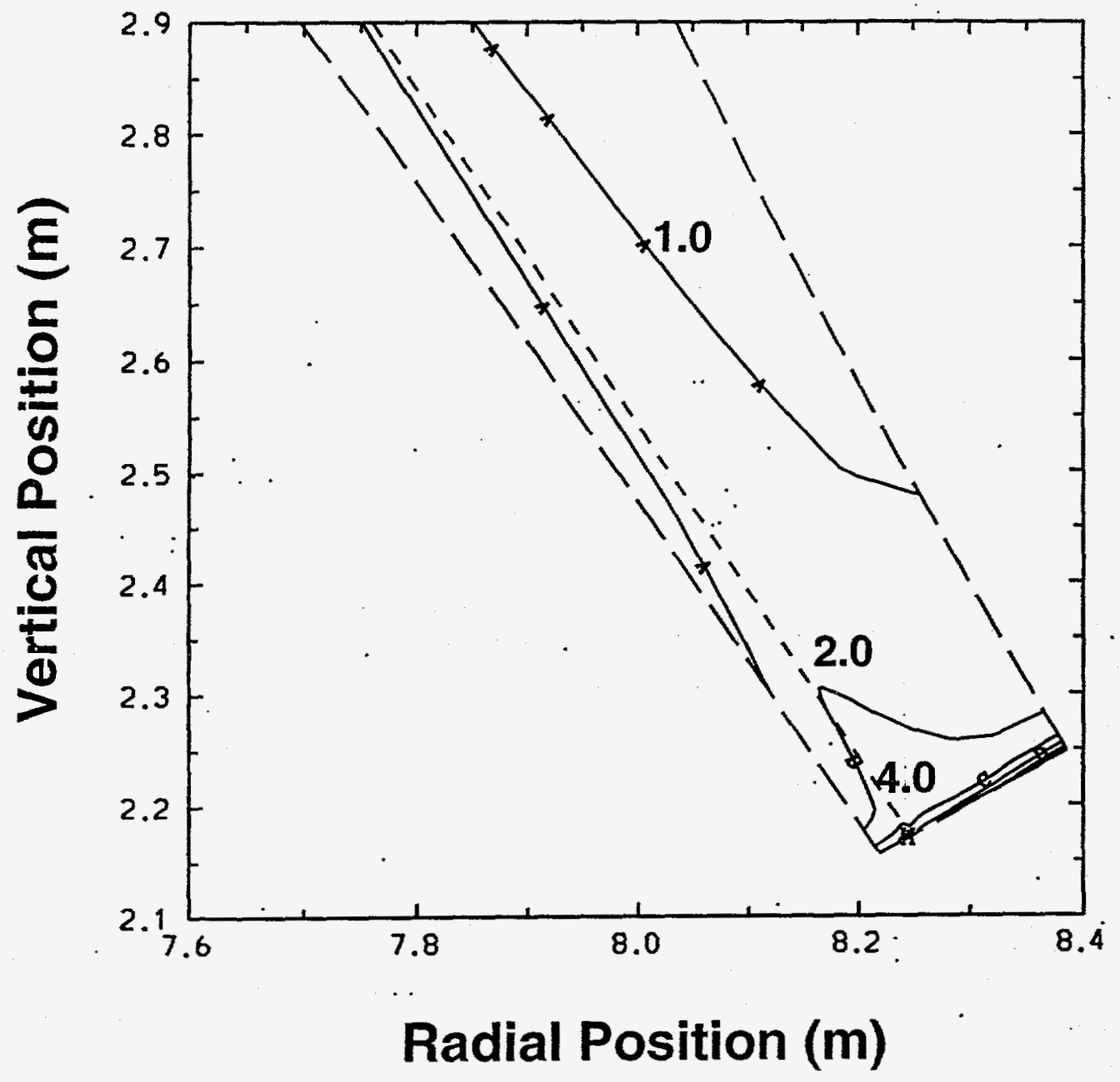

ni.H.ortid 


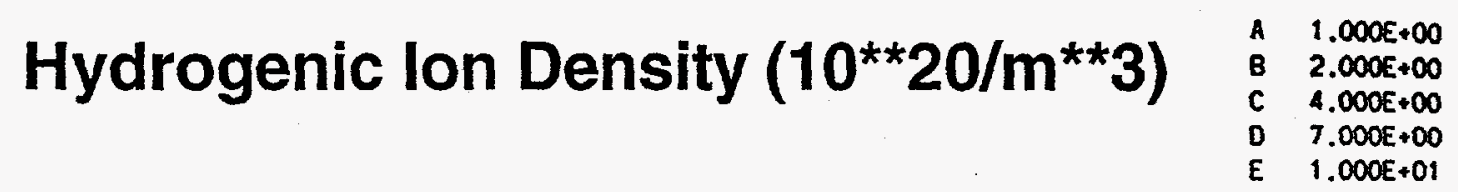

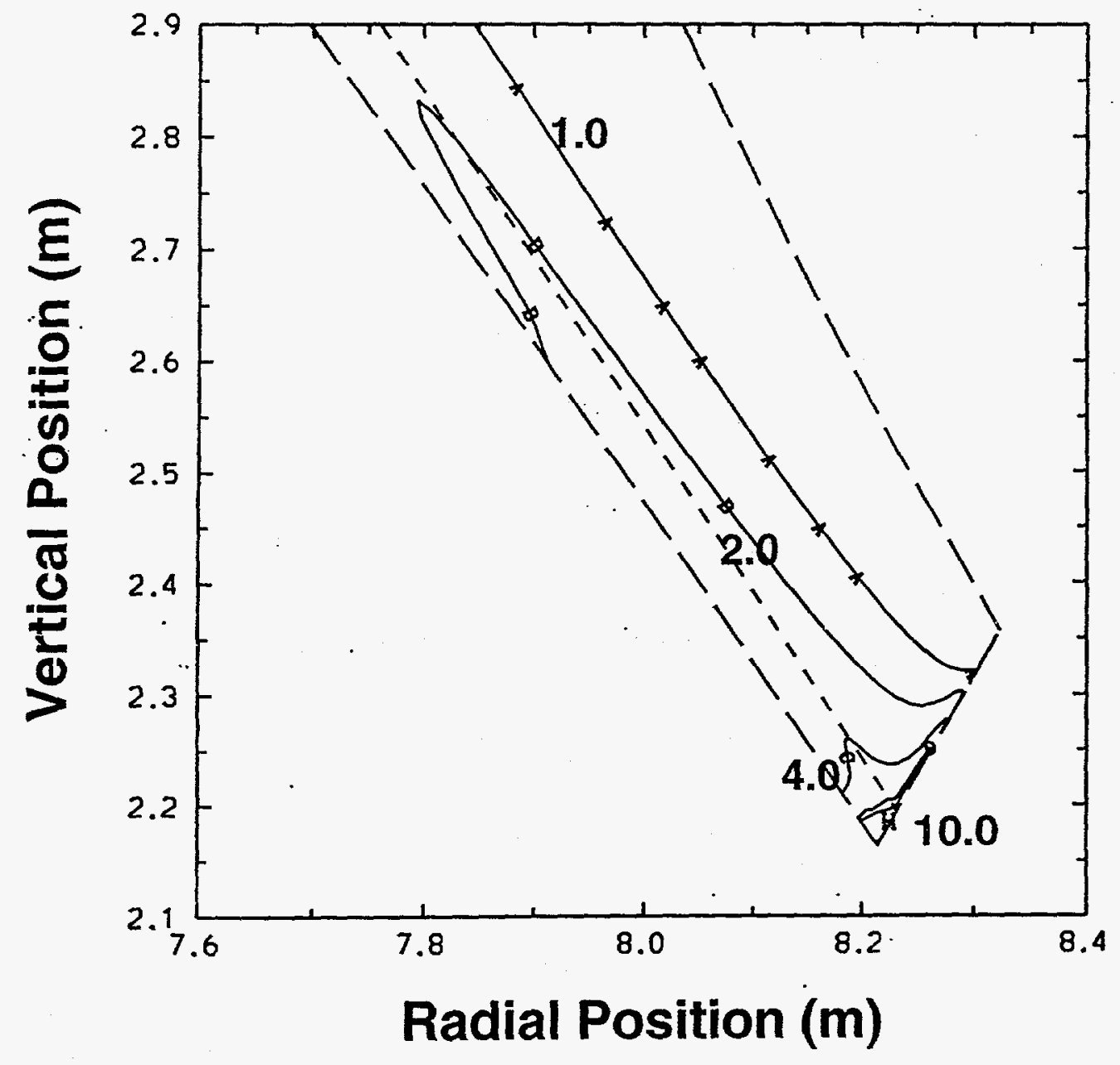

nithtilt id 


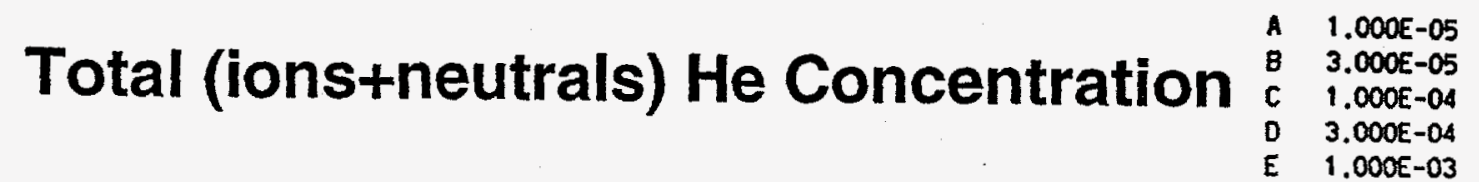

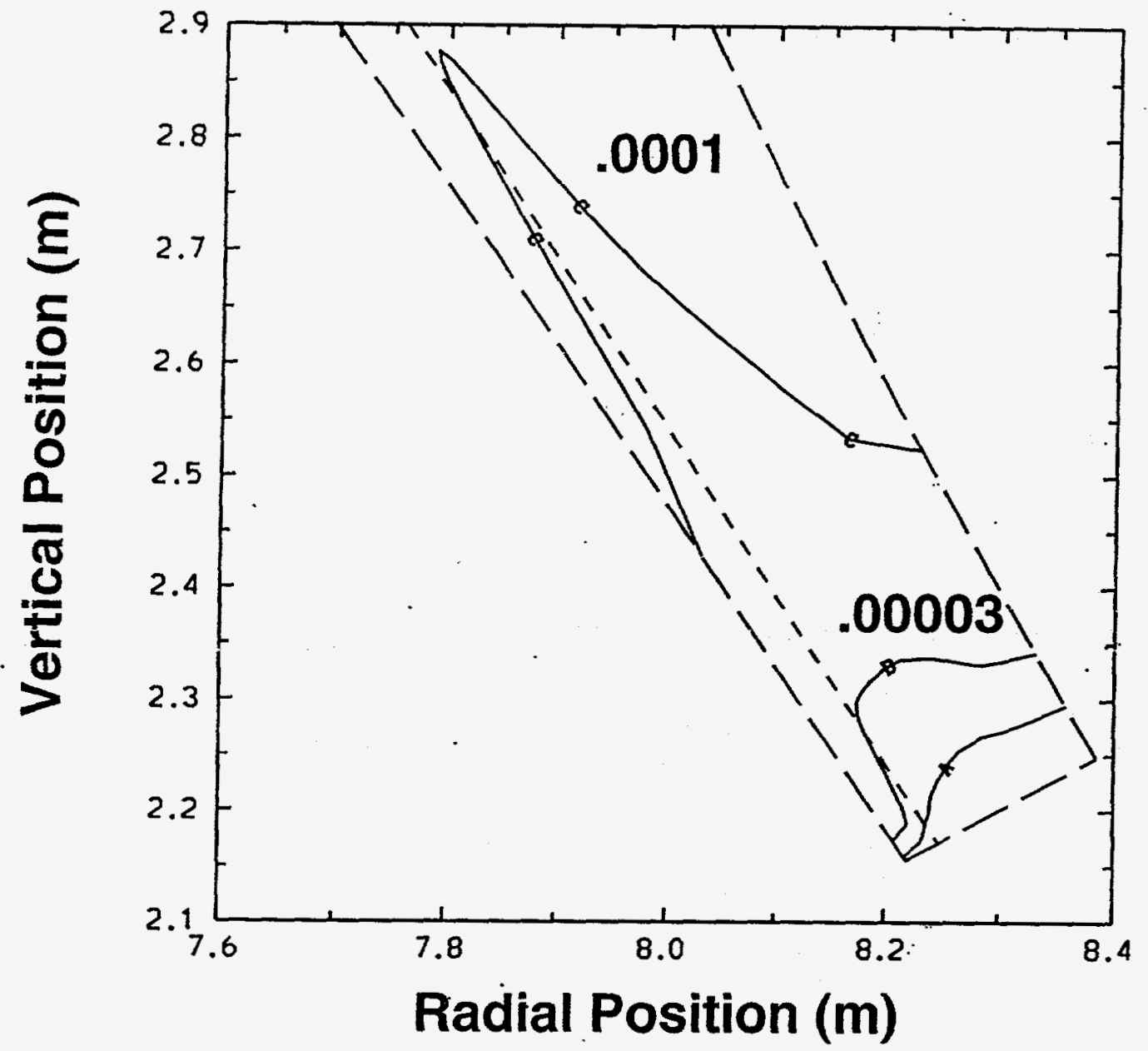




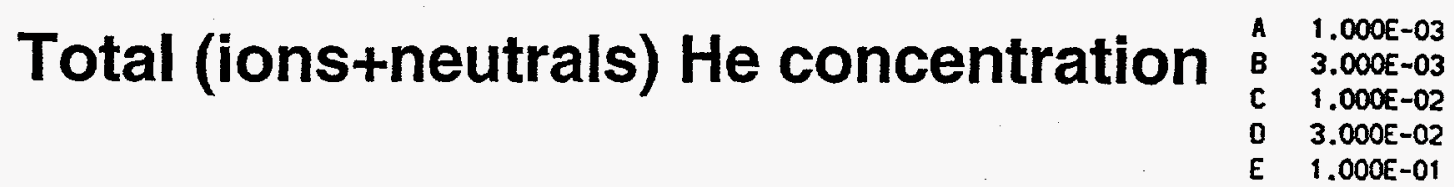

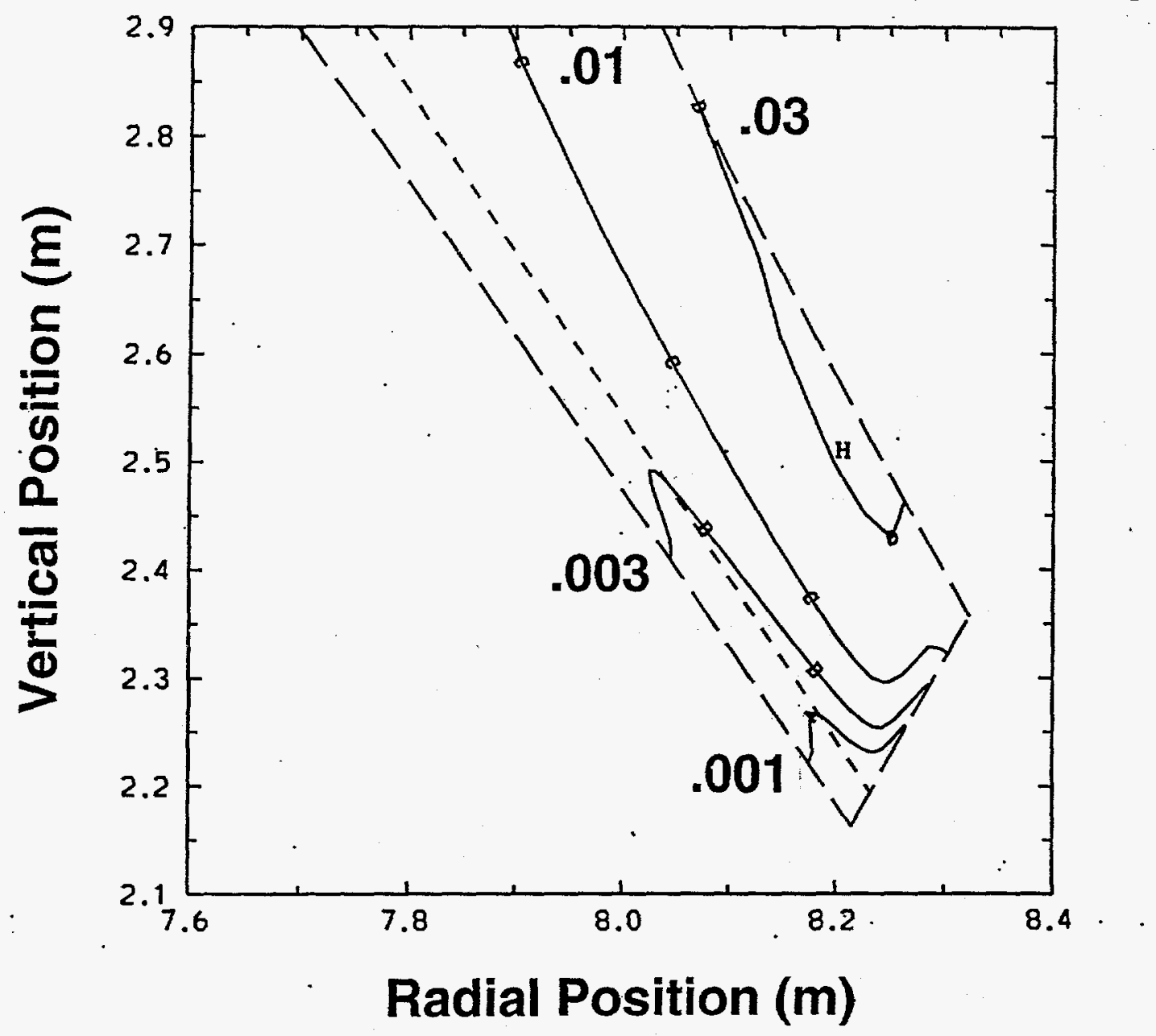

cz.He.tilt.id 


\section{Total (ions+neutrals) He particle flux}

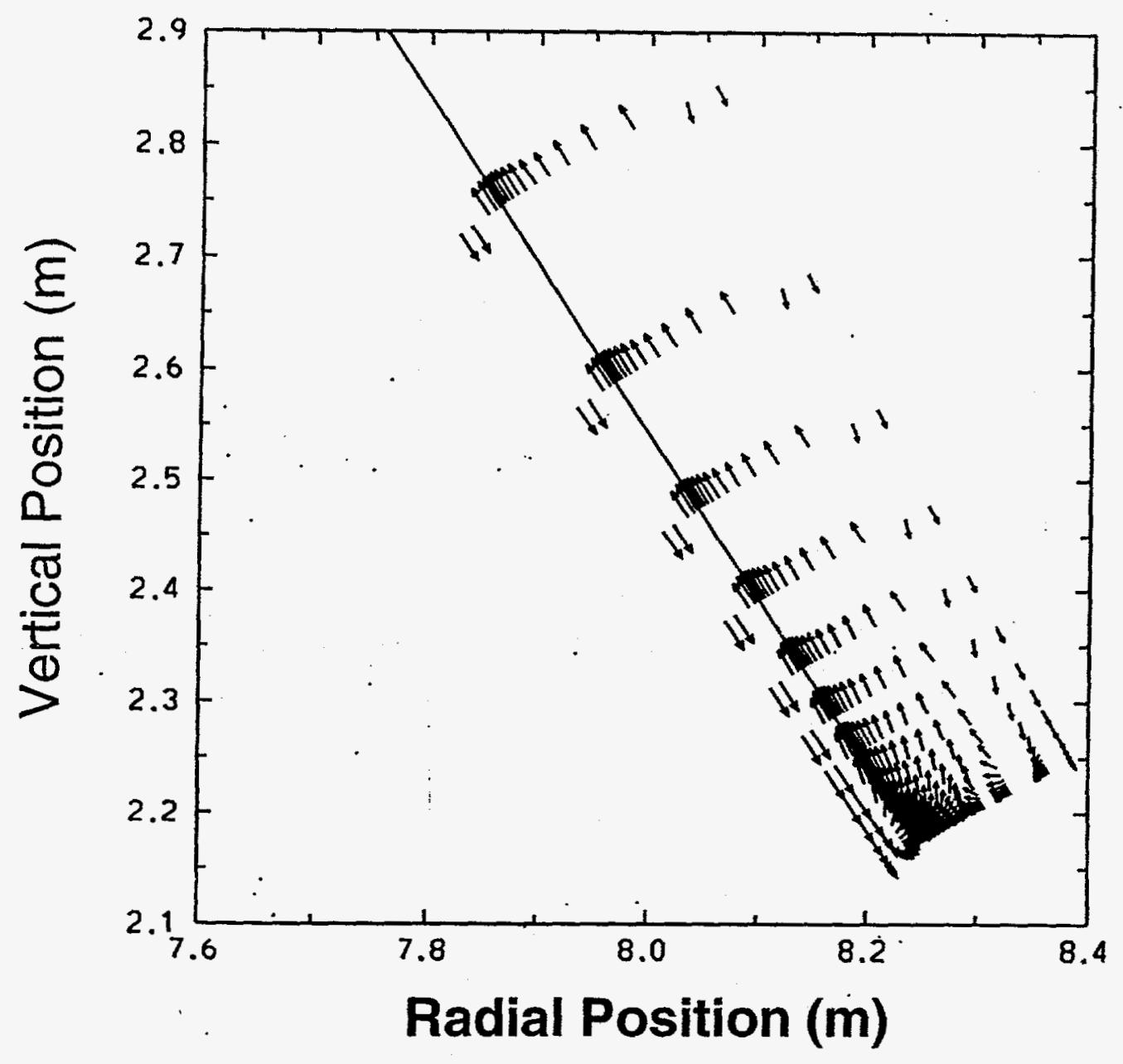

flow. He.ortid 


\section{Total (ions+neutrals) He particle flux}

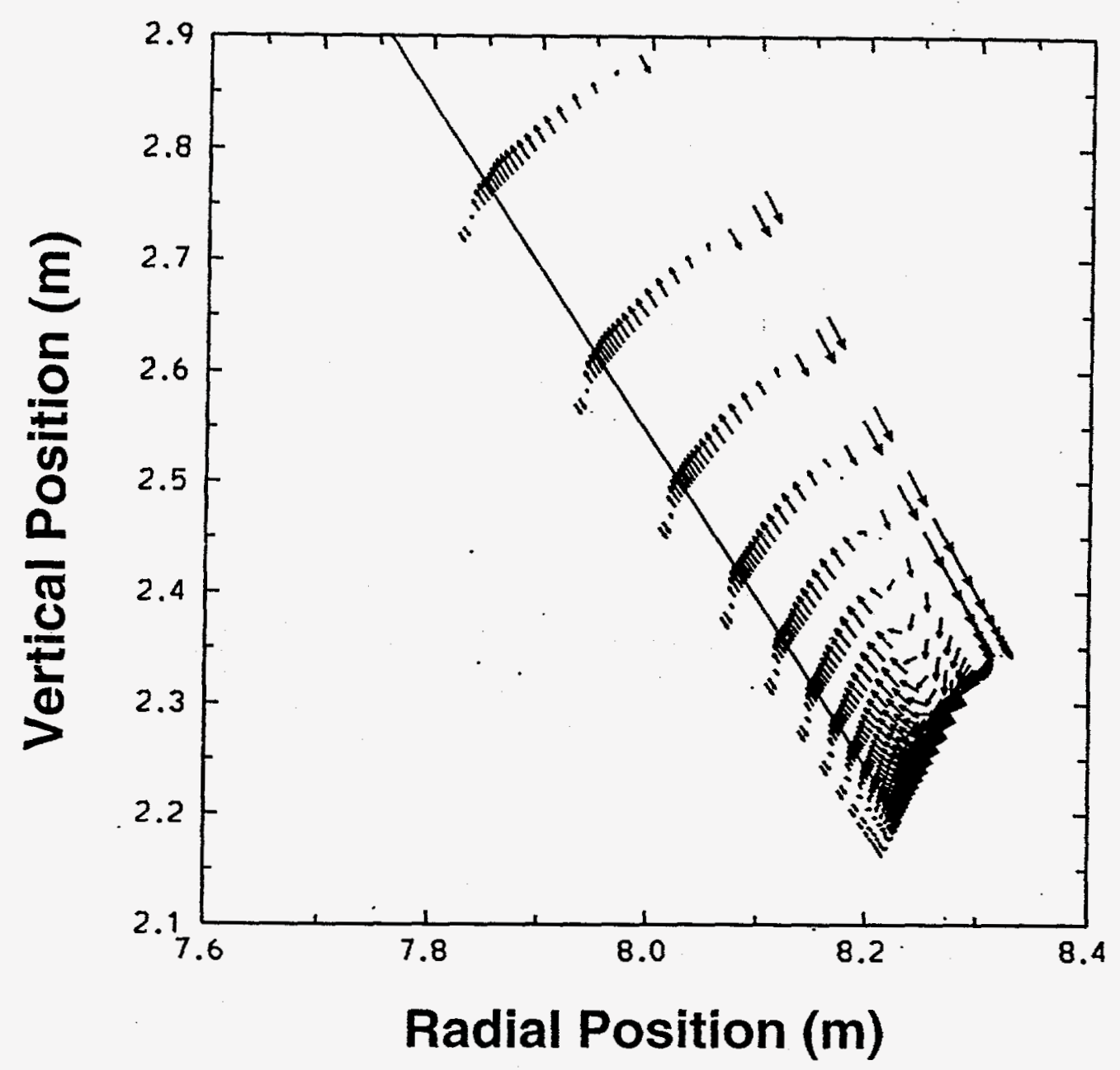

0.4948+11

waxaMUN VECTOR

flow. He.tilt id, 


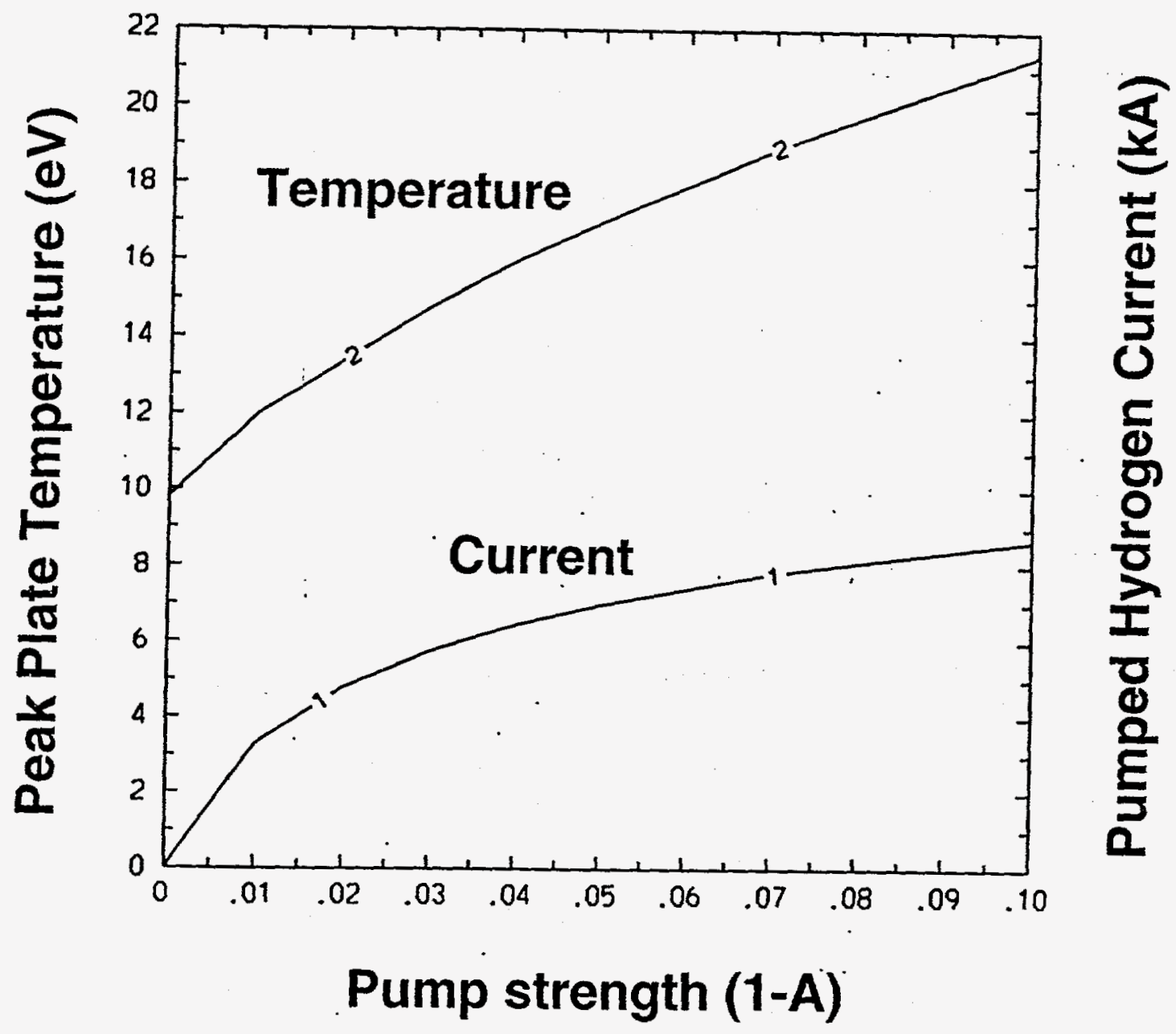




\section{Neon Radiation (MW/m**3)}

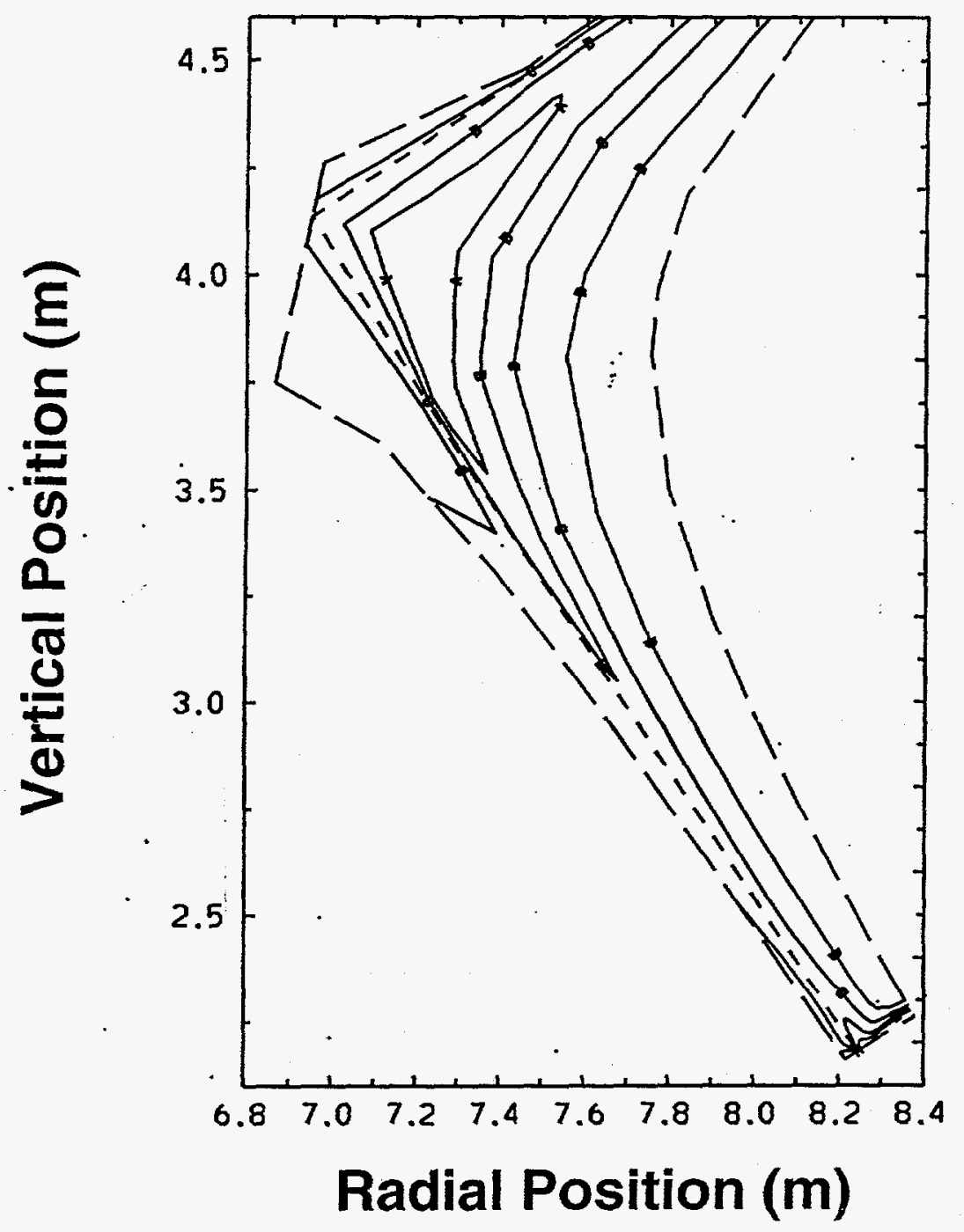




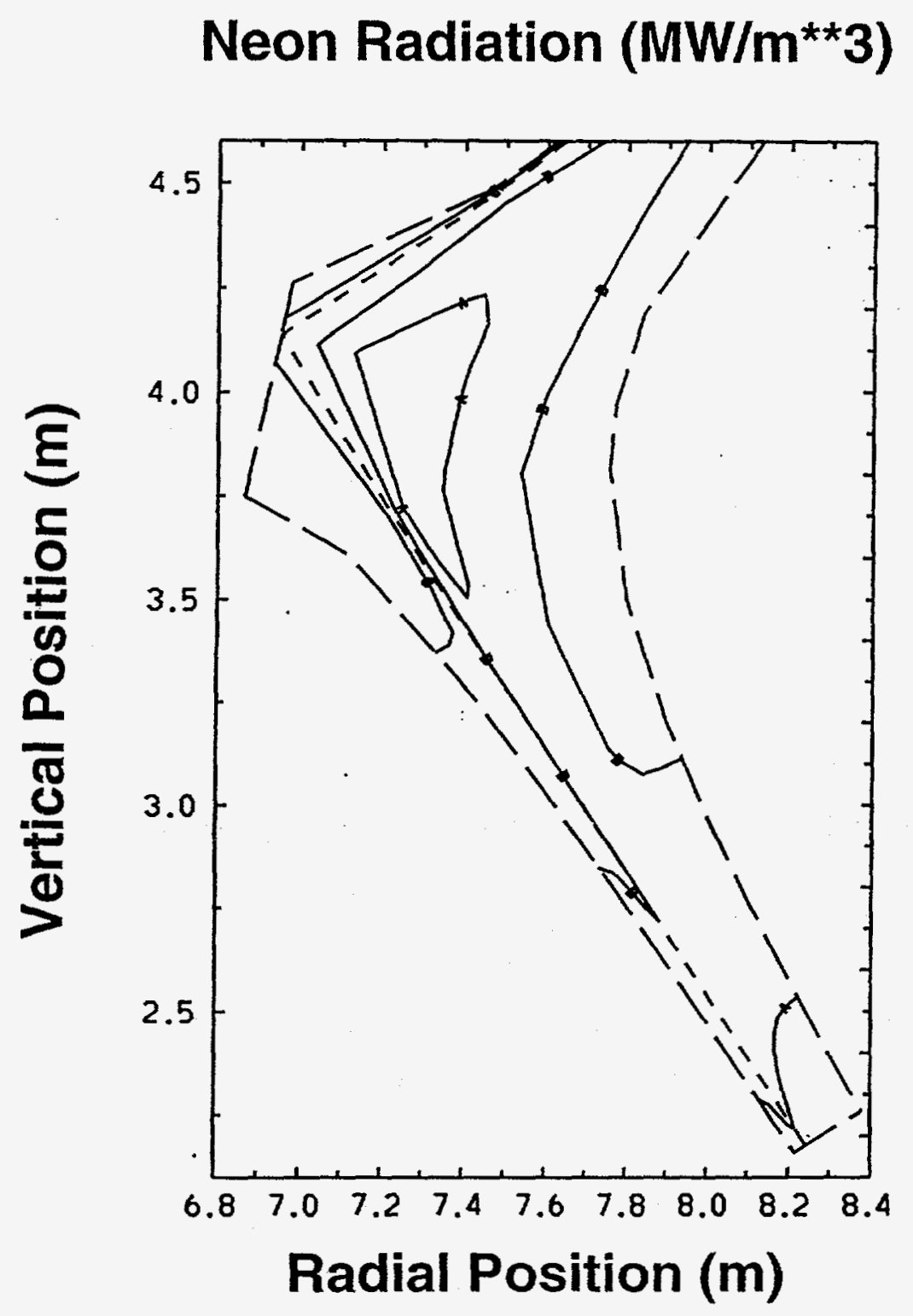




\section{Total (ions+neutrals) Ne Concentration}

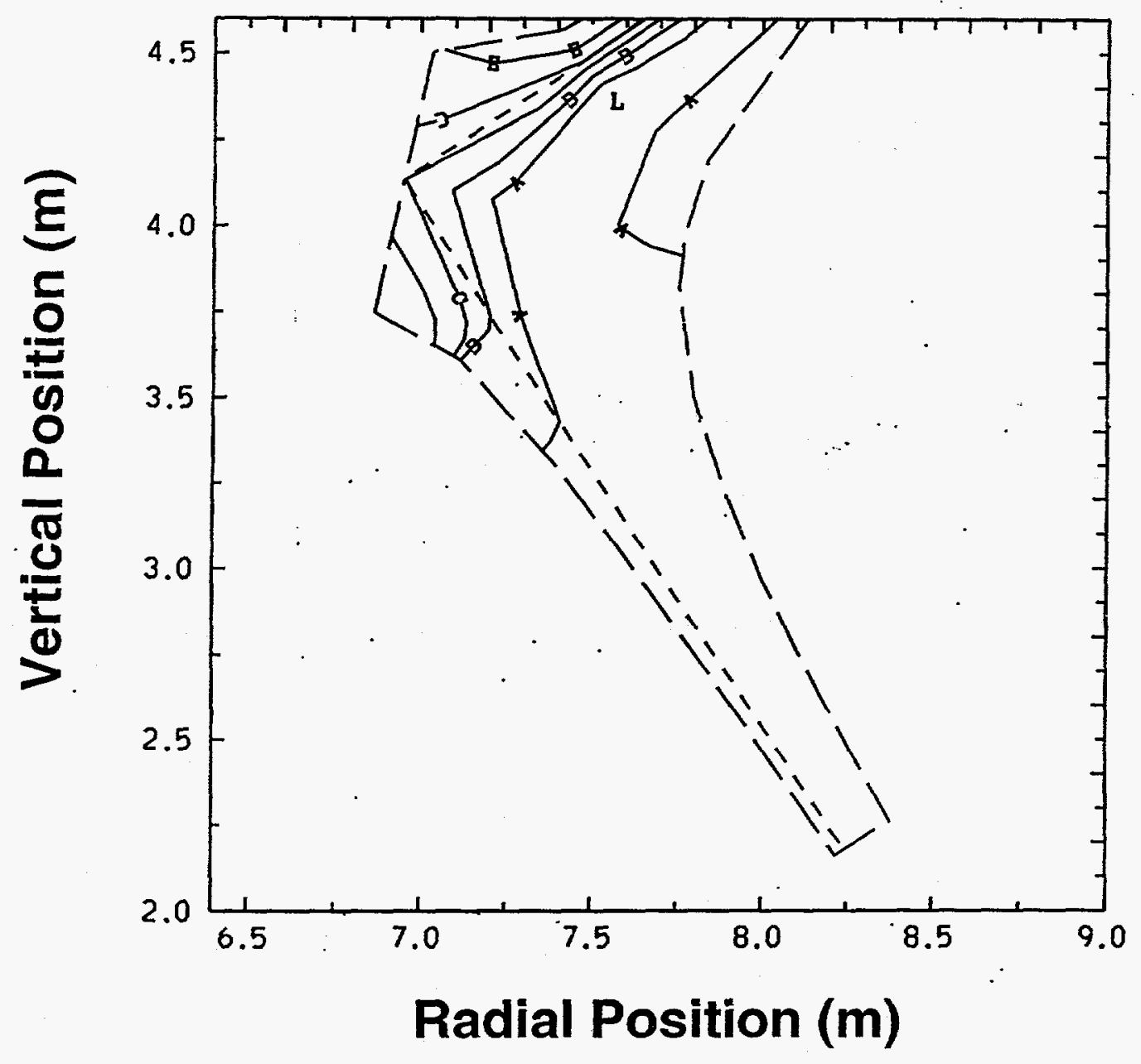

A 1.000E-05

B 3.000E-05

C 1.000E-04

D 3.000E-04

E $1.000 E-03$

F 3.000E-03

C $1.000 E-02$

\section{Radial Position (m)}




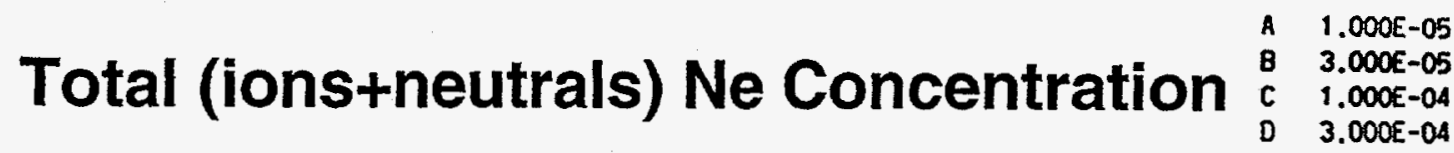

D $\quad 3.000 E-04$

f. 3.000E-03

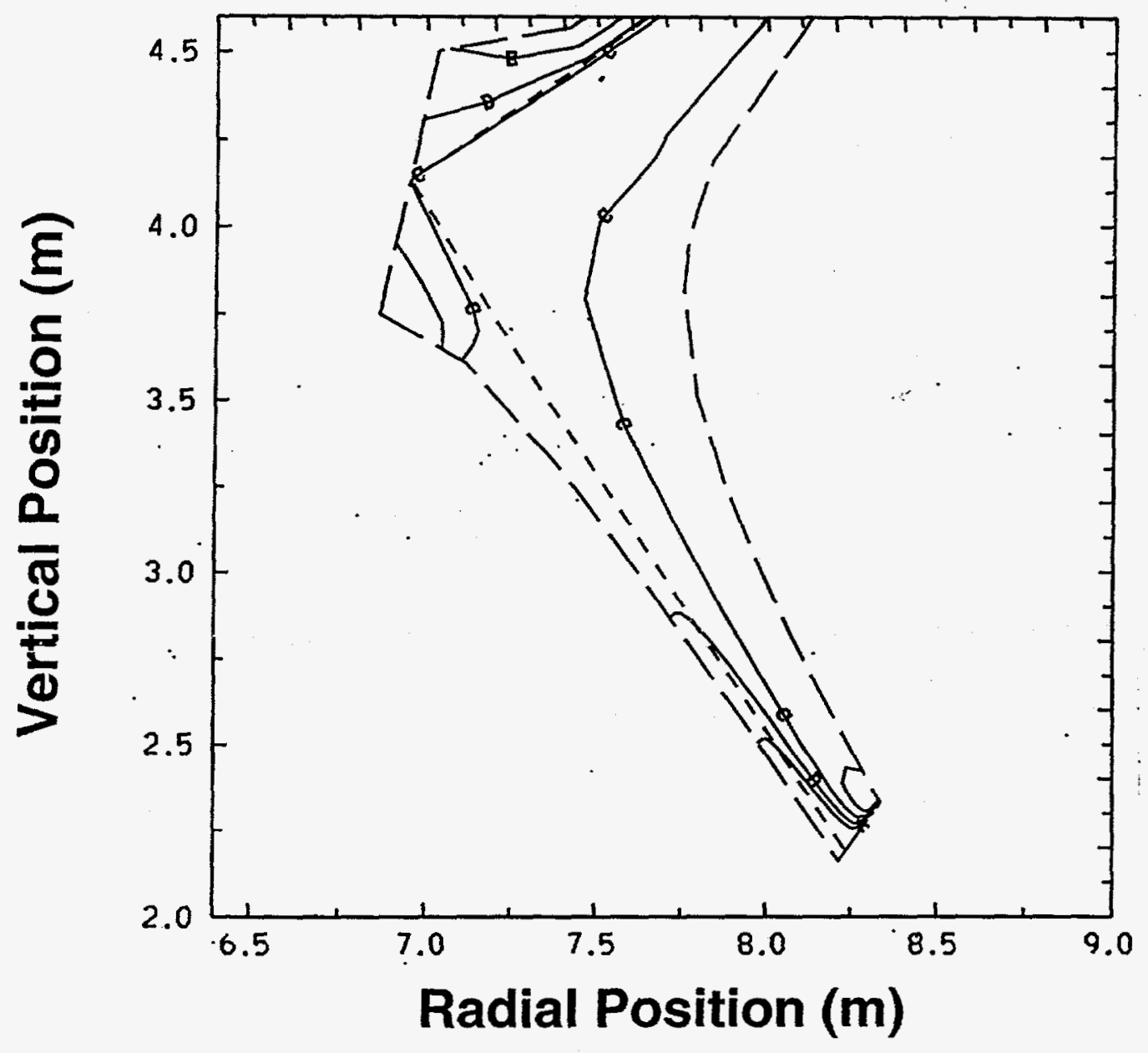

conc Ne_tilt.id 
Fig. $13 a$

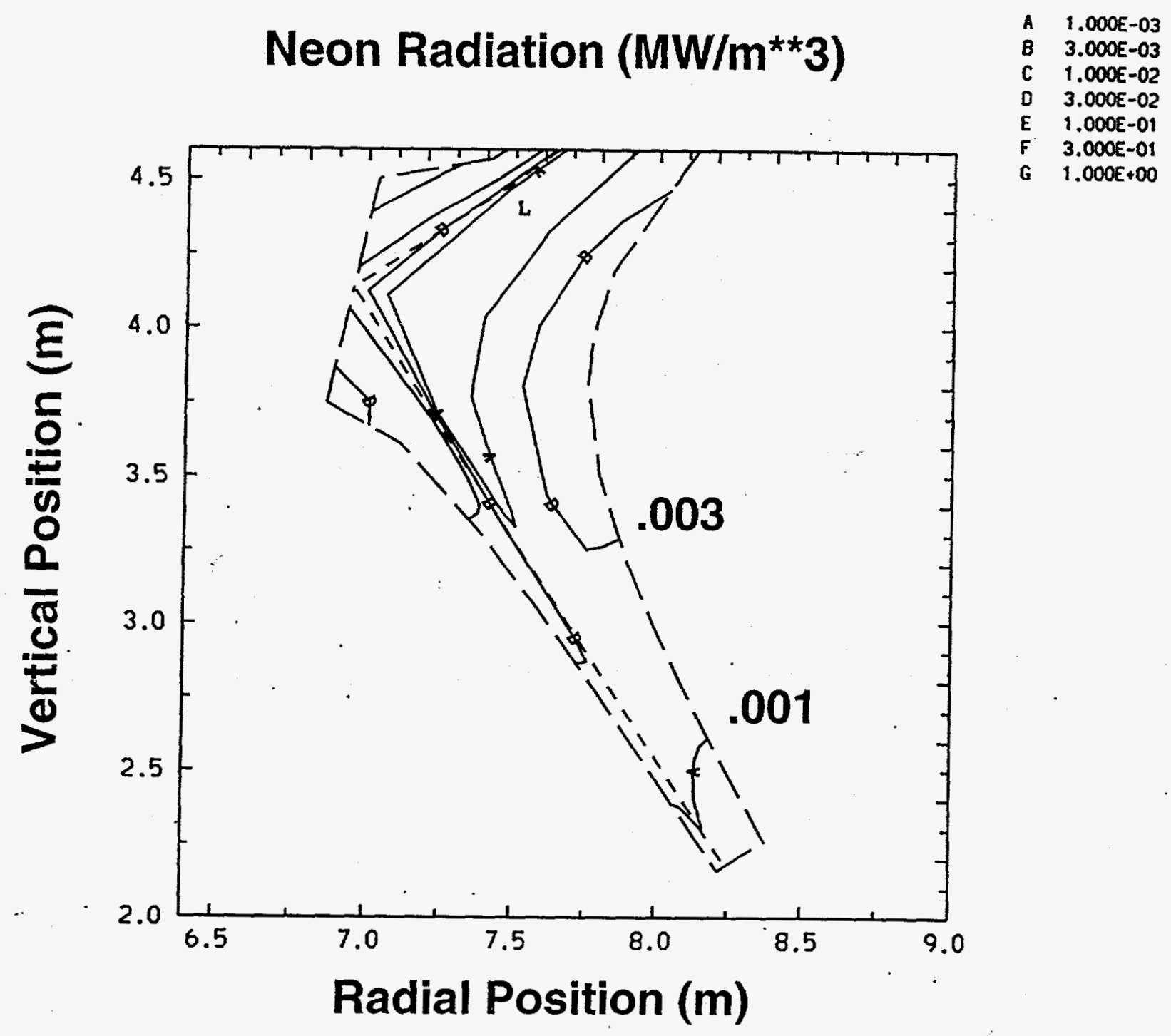

pradNe_ort id 
Fig. 136

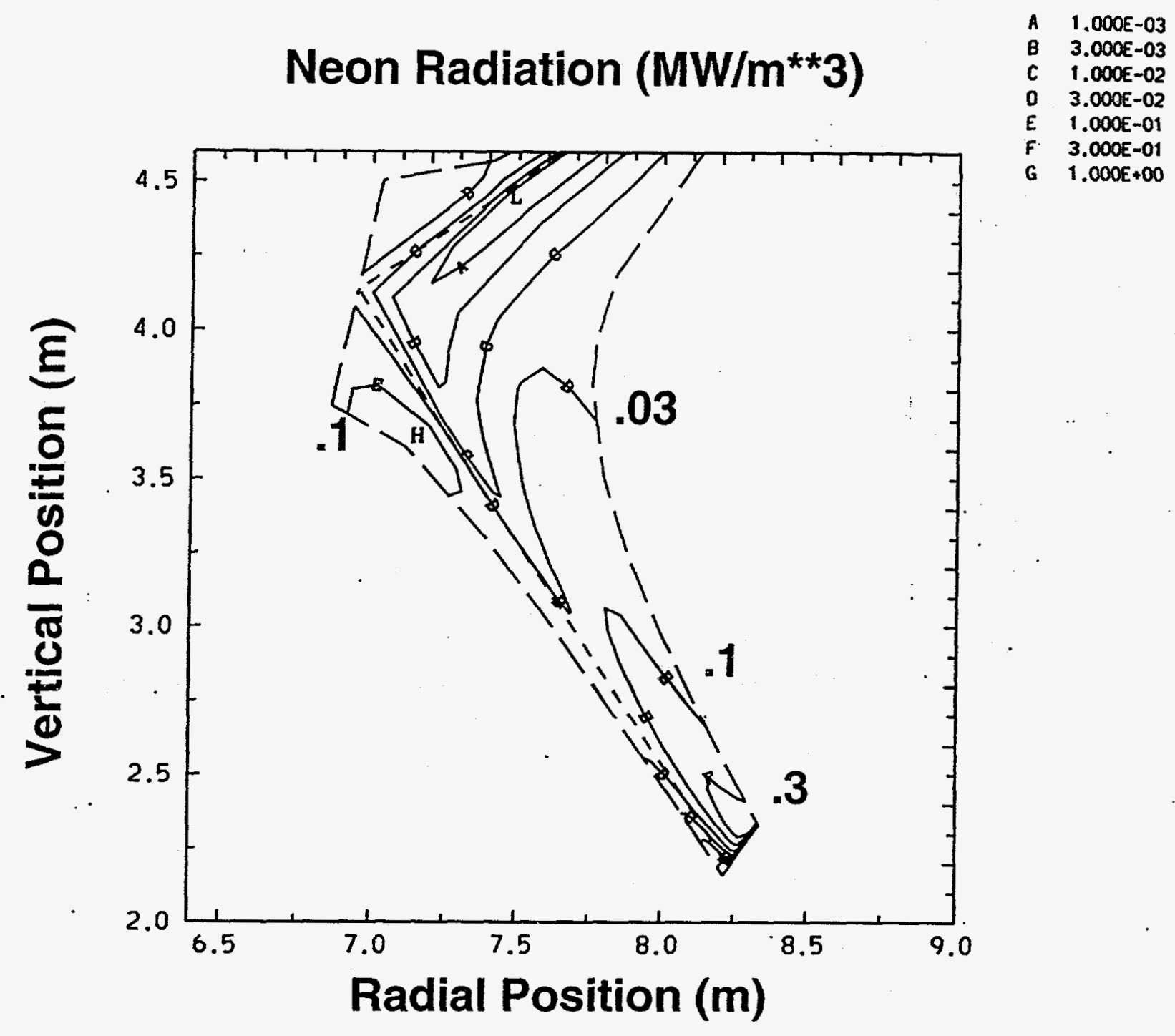

pradNe_tilt.id 


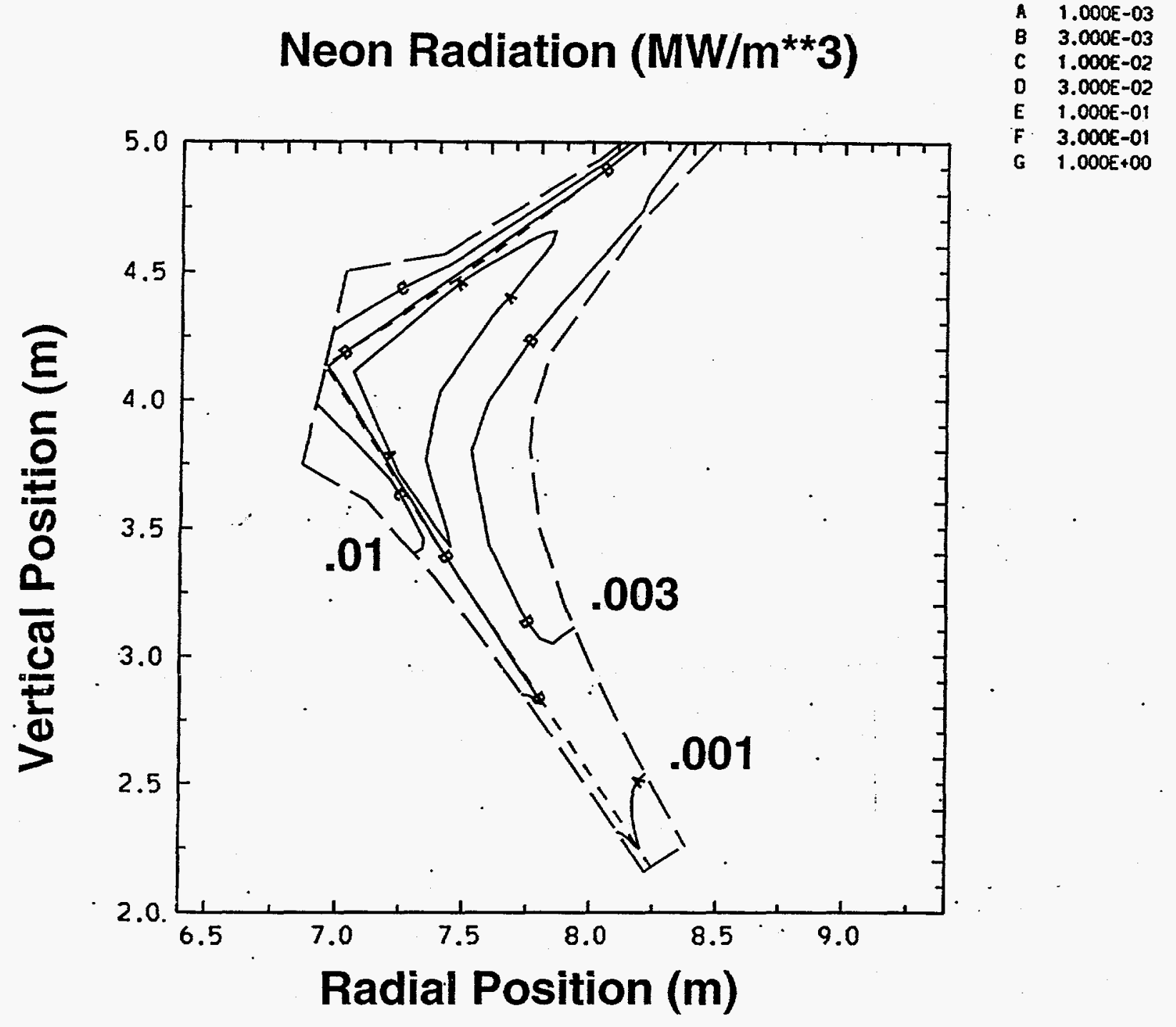

pradz_on.id 
Fig. $14 b$

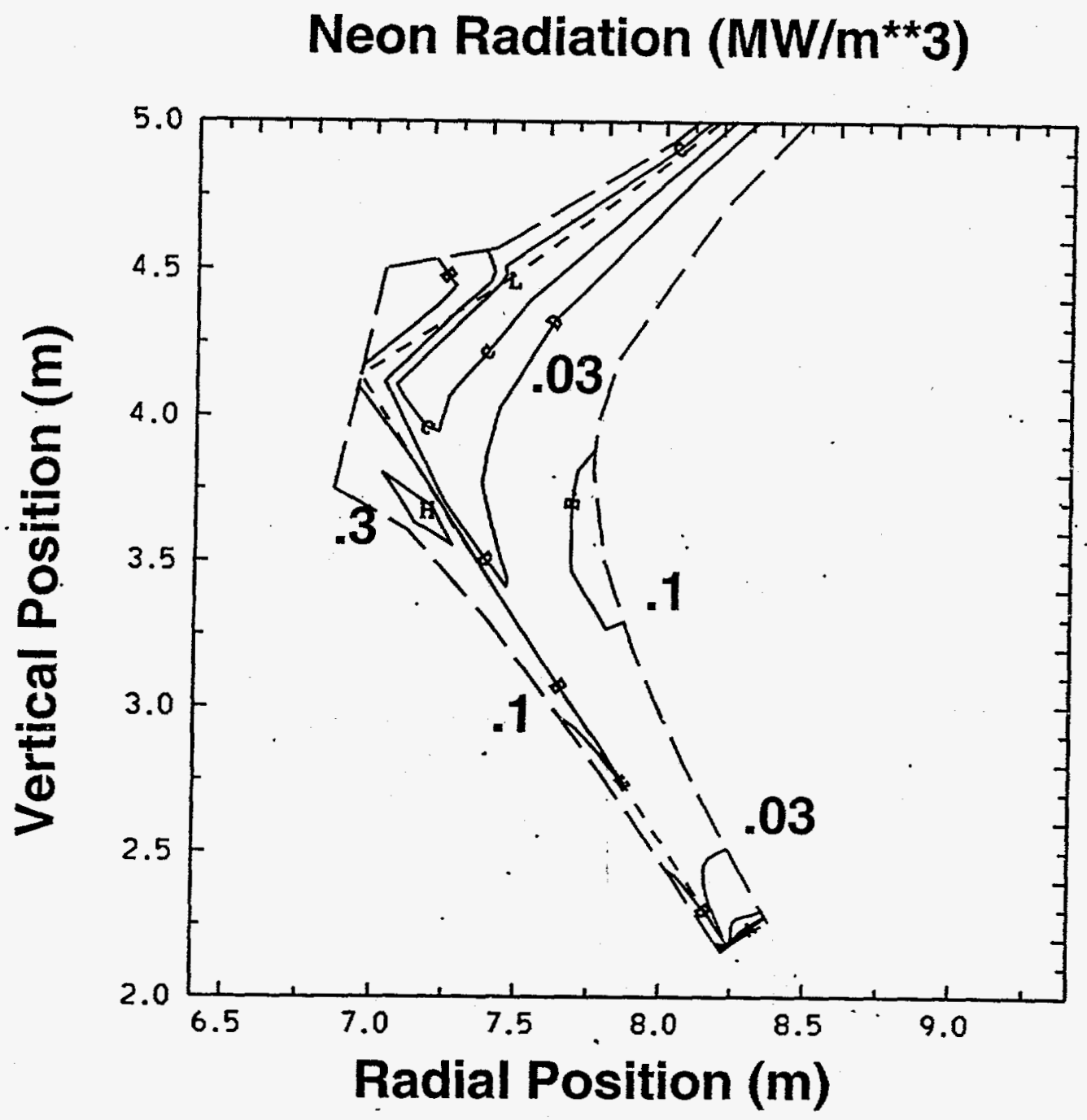

pradz_off.id 
Fig. 15 a

Total (ions+neutrals) Ne Density

$\left(10^{\star \star} 20 / \mathrm{m}^{\star \star} 3\right)$

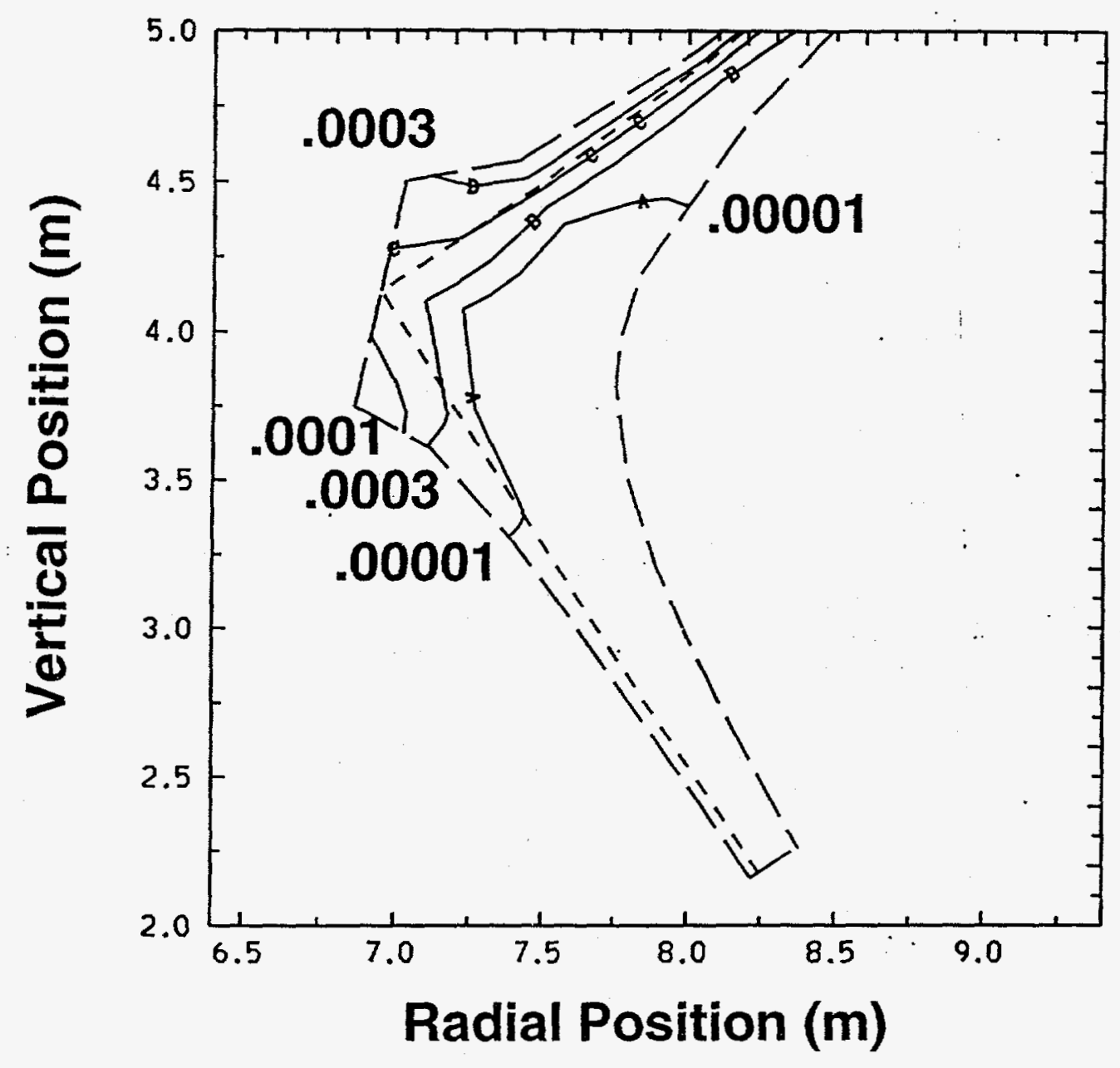

$n z$ on.id 


\section{Total (ions+neutrals) Ne density $\left(10^{\star \star} 20 / \mathrm{m}^{\star *} 3\right)$}

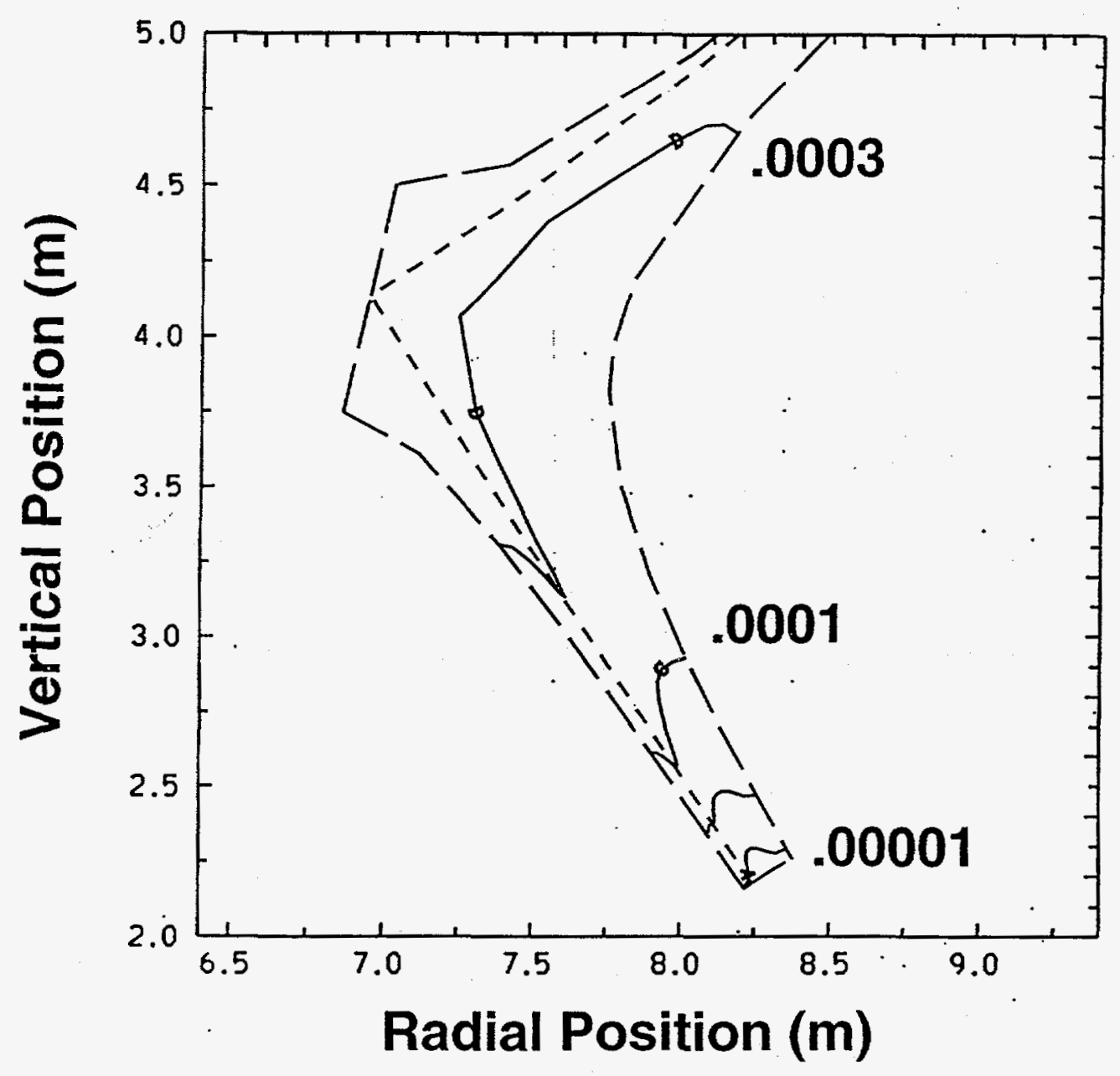




\begin{tabular}{|c|c|c|}
\hline & Inner Plate & Outer Plate \\
\hline Total Power (MW) & 51.0 & 89.5 \\
\hline Peak Power $\left(M W / m^{\star \star} 2\right)$ & 49.4 & 58.9 \\
\hline Peak Electron Temperature (eV) & 13.7 & 12.1 \\
\hline Peak lon Temperature (eV) & 2.7 & 2.5 \\
\hline Peak Ion Density $\left(10^{\star \star} 20 / \mathrm{m}^{\star \star} 3\right)$ & 11.9 & 11.8 \\
\hline Peak Neutral Density $\left(10^{\star \star} 20 / \mathrm{m}^{\star \star} 3\right)$ & 19.0 & 13.2 \\
\hline
\end{tabular}




\begin{tabular}{|c|c|c|}
\hline $\begin{array}{c}\text { TABLE 2: Full single-null simulation with P_core_e }=\text { P_core_i }=75 \mathrm{MW} \\
\text { and diffusion coefficients }=(0.67,1.00,1.00) \\
\end{array}$ & Inner Plate & Outer Plate \\
\hline Total Power $(\mathrm{MW})$ & 50.7 & 89.0 \\
\hline Peak Power $\left(\mathrm{MW} / \mathrm{m}^{\star \star} 2\right)$ & 32.6 & 38.3 \\
\hline Peak Electron Temperature (eV) & 10.0 & 8.7 \\
\hline Peak Ion Temperature $(\mathrm{eV})$ & 2.6 & 2.4 \\
\hline Peak Ion Density $\left(10^{\star \star} 20 / \mathrm{m}^{\star \star} 3\right)$ & 10.5 & 10.5 \\
\hline Peak Neutral Density $\left(10^{\star \star} 20 / \mathrm{m}^{\star \star} 3\right)$ & 12.6 & 10.5 \\
\hline
\end{tabular}




\begin{tabular}{|c|c|c|}
\hline \multicolumn{3}{|c|}{ 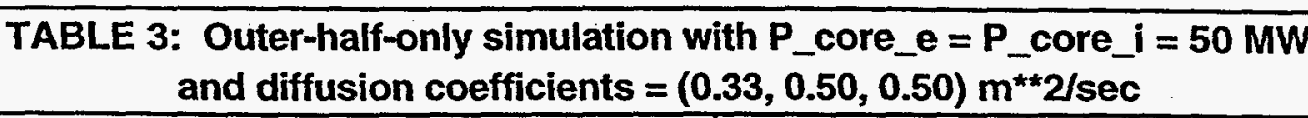 } \\
\hline & Inner Plate & Outer Plate \\
\hline Total Power (MW) & & 96.6 \\
\hline Peak Power (MW/m*^2) & & 72.5 \\
\hline Peak Electron Temperature (eV) & & 25.5 \\
\hline Peak lon Temperature (eV) & & 3.1 \\
\hline Peak Ion Density $\left(10^{\star \star} 20 / \mathrm{m}^{\star \star} 3\right)$ & & 7.7 \\
\hline Peak Neutral Density $\left(10^{\star \star} 20 / \mathrm{m}^{\star \star} 3\right)$ & $\therefore$ & $\overline{7.2}$ \\
\hline
\end{tabular}




\begin{tabular}{|c|c|c|c|c|}
\hline $\begin{array}{c}\text { Core Neon } \\
\text { Concentration }\end{array}$ & $\begin{array}{c}\text { Core Hydrogen } \\
\text { Density } \\
\left(10^{\star \star} 19 / \mathrm{m}^{\star \star} 3\right)\end{array}$ & $\begin{array}{c}\text { Radial } \\
\text { Diffusion }\end{array}$ & $\begin{array}{l}\text { Total Hydrogen } \\
\text { Radiation (MW) }\end{array}$ & $\begin{array}{c}\text { Total Neon } \\
\text { Radiation (MW) }\end{array}$ \\
\hline .0067 & 3.0 & weak & 5.5 & 13.6 \\
\hline .01 & 3.0 & weak & 6.2 & 25.1 \\
\hline .002 & 5.0 & weak & 6.2 & 5.9 \\
\hline .004 & 5.0 & weak & 7.5 & 24.5 \\
\hline .002 & 5.0 & strong & 6.7 & 3.4 \\
\hline .004 & 5.0 & strong & 6.5 & 7.2 \\
\hline .006 & 5.0 & strong & 6.4 & 11.8 \\
\hline .008 & 5.0 & strong & 6.3 & 17.9 \\
\hline .0085 & 5.0 & strong & 6.4 & 20.3 \\
\hline
\end{tabular}




\begin{tabular}{|c|c|c|}
\hline \multicolumn{1}{|c|}{\begin{tabular}{c} 
TABLE 1: Full single-null simulation with P_core_e $=$ P_core_i $=75 \mathrm{MW}$ \\
and diffusion coefficients $=(0.33,0.50,0.50)$ \\
\hline
\end{tabular}} & $\begin{array}{c}\text { Inner Plate } \\
\text { Total Power }(\mathrm{MW})\end{array}$ & Outer Plate \\
\hline Peak Power $\left(\mathrm{MW} / \mathrm{m}^{\star \star} 2\right)$ & 51.0 & 89.5 \\
\hline Peak Electron Temperature (eV) & 49.4 & 58.9 \\
\hline Peak Ion Temperature (eV) & 13.7 & 12.1 \\
\hline Peak Ion Density $\left(10^{\star \star} 20 / \mathrm{m}^{\star \star} 3\right)$ & 2.7 & 2.5 \\
\hline Peak Neutral Density $\left(10^{\star \star} 20 / \mathrm{m}^{\star \star} 3\right)$ & 11.9 & 11.8 \\
\hline
\end{tabular}




\begin{tabular}{|c|c|c|}
\begin{tabular}{c} 
TABLE 2: Full single-null simulation with P_core_e $=$ P_core_i $=75 \mathrm{MW}$ \\
and diffusion coefficients $=(0.67,1.00,1.00)$ \\
\hline
\end{tabular} & Inner Plate & Outer Plate \\
\hline Total Power $(\mathrm{MW})$ & 50.7 & 89.0 \\
\hline Peak Power $\left(\mathrm{MW} / \mathrm{m}^{\star \star} 2\right)$ & 32.6 & 38.3 \\
\hline Peak Electron Temperature $(\mathrm{eV})$ & 10.0 & 8.7 \\
\hline Peak Ion Temperature $(\mathrm{eV})$ & 2.6 & 2.4 \\
\hline Peak Ion Density $\left(10^{\star \star} 20 / \mathrm{m}^{\star \star} 3\right)$ & 10.5 & 10.5 \\
\hline Peak Neutral Density $\left(10^{\star \star} 20 / \mathrm{m}^{\star \star} 3\right)$ & 12.6 & 10.5 \\
\hline
\end{tabular}




\begin{tabular}{|c|c|c|}
\hline \begin{tabular}{c} 
TABLE 3: Outer-half-only simulation with P_core_e $=$ P_core_i $=50 \mathrm{MW}$ \\
and diffusion coefficients $=(0.33,0.50,0.50)$ \\
\hline
\end{tabular} & Inner Plate & Outer Plate \\
\hline Total Power $(\mathrm{MW})$ & & 96.6 \\
\hline Peak Power $\left(\mathrm{MW} / \mathrm{m}^{\star \star} 2\right)$ & & 72.5 \\
\hline Peak Electron Temperature $(\mathrm{eV})$ & & 25.5 \\
\hline Peak Ion Temperature $(\mathrm{eV})$ & & 3.1 \\
\hline Peak Ion Density $\left(10^{\star \star} 20 / \mathrm{m}^{\star \star} 3\right)$ & & 7.7 \\
\hline Peak Neutral Density $\left(10^{\star \star} 20 / \mathrm{m}^{\star \star} 3\right)$ & & 7.2 \\
\hline
\end{tabular}


TABLE 4: Radiated Power for various densities and diffusion strengths Outer-half-space simulation with $\mathrm{P} \_$core_e $=\mathrm{P}_{\text {c core }} \mathrm{i}=50 \mathrm{MW}$

\begin{tabular}{|c|c|c|c|c|}
\hline $\begin{array}{c}\text { Core Neon } \\
\text { Concentration }\end{array}$ & $\begin{array}{c}\text { Core Hydrogen } \\
\text { Density } \\
\left(10^{\star \star} 19 / \mathrm{m}^{\star \star} 3\right)\end{array}$ & $\begin{array}{c}\text { Radial } \\
\text { Diffusion }\end{array}$ & $\begin{array}{c}\text { Total Hydrogen } \\
\text { Radiation }(\mathrm{MW})\end{array}$ & $\begin{array}{c}\text { Total Neon } \\
\text { Radiation }(\mathrm{MW})\end{array}$ \\
\hline .0067 & 3.0 & weak & 5.5 & 13.6 \\
\hline .01 & 3.0 & weak & 6.2 & 25.1 \\
\hline .002 & 5.0 & weak & 6.2 & 5.9 \\
\hline .004 & 5.0 & weak & 7.5 & 24.5 \\
\hline .002 & 5.0 & strong & 6.7 & 3.4 \\
\hline .004 & 5.0 & strong & 6.5 & 7.2 \\
\hline .006 & 5.0 & strong & 6.4 & 11.8 \\
\hline .008 & 5.0 & strong & 6.3 & 17.9 \\
\hline .0085 & 5.0 & strong & 6.4 & 20.3 \\
\hline
\end{tabular}

